\title{
Biopolymer-based flocculants: a review of recent technologies
}

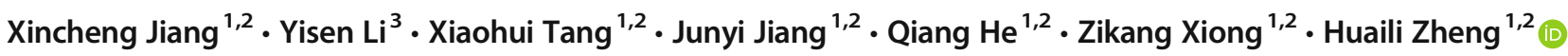

Received: 4 March 2021 / Accepted: 30 June 2021 / Published online: 14 July 2021

(C) The Author(s), under exclusive licence to Springer-Verlag GmbH Germany, part of Springer Nature 2021

\begin{abstract}
Biopolymer-based flocculants have become a potential substitute for inorganic coagulants and synthetic organic flocculants due to their wide natural reserves, environmental friendliness, easy natural degradation, and high material safety. In recent years, with more and more attention to clean technologies, a lot of researches on the modification and application of biopolymer-based flocculants have been carried out. The present paper reviews the latest important information about the base materials of biopolymer-based flocculants, including chitosan, starch, cellulose, and lignin etc. This review also highlights the various modification methods of these base materials according to reaction types in detail. Via the recent researches, the flocculation mechanisms of biopolymer-based flocculants, such as adsorption, bridging, charge neutralization, net trapping, and sweeping, as well as, some other special mechanisms are comprehensively summarized. This paper also focuses on the water treatment conditions, the removal efficiency, and advantages of biopolymer-based flocculants in applications. Further, this review sheds light on the future perspectives of biopolymer-based flocculants, which may make progress in the sources of base materials, modification processes, multi-function, and deepening application researches. We believe that this review can guide the further researches and developments of biopolymer-based flocculants in the future, to develop them with a higher efficiency, a lower cost, more safety, and multi-function for more diversified applications.
\end{abstract}

Keywords Biopolymer-based flocculants $\cdot$ Flocculation $\cdot$ Modification methods $\cdot$ Flocculation mechanisms $\cdot$ Water treatment

\section{Introduction}

With the progress of human development, the discharged sewage becomes diversified, which has an increasingly detrimental impact on the ecological environment. Besides, about onefifth of the world's population has no access to safe water, so pathogens in the water cause about 5500 deaths per day (Schwarzenbach et al. 2006). Therefore, the increasingly serious pollution of natural water has a long-term negative impact on the ecological environment and human health. To solve

Responsible Editor: Angeles Blanco

Huaili Zheng

hlz6512@163.com

1 State Key Laboratory of Coal Mine Disaster Dynamics and Control, Chongqing University, Chongqing 400044, People's Republic of China

2 Key Laboratory of the Three Gorges Reservoir Region's Eco-Environment, State Ministry of Education, Chongqing University, Chongqing 400045, People's Republic of China

3 Digital Chongqing Big Data Application Development Co., Ltd, Chongqing 400000, People's Republic of China this problem, researches on water treatment methods have begun to increase. At present, water treatment technologies mainly include coagulation/flocculation (Rajala et al. 2020), adsorption (Zheng et al. 2019), ion exchange (Can et al. 2020), advanced oxidation (Wang et al. 2019a), biological treatment (Lin et al. 2019), and membrane filtration (Fu and Zhang 2018), etc.

As one of the water treatment technologies, flocculation is used to promote the solid-liquid separation of colloidal suspension (Dao et al. 2016). It has advantages of a low investment cost, high treatment efficiency and simple operation (Dao et al. 2016; Yang et al. 2016a). Flocculation can effectively deal with various types of water pollution, such as turbidity, dyes, heavy metal ions, other industrial/ agricultural wastewater, algae, and sludge dewatering. Therefore, it can be called a very economical and effective water treatment method.

Flocculant is a kind of water treatment agent. It can aggregate the colloidal substances and particulate matters suspended in the liquid to form larger flocs, and then promote the settlement of these particles from the stable suspension (Salehizadeh et al. 2018). As the core of flocculation, flocculants' characteristics directly determine the efficiency of water 
treatment (Liao et al. 2014). According to the chemical composition, the flocculant can be divided into inorganic coagulants and organic flocculants. The inorganic coagulants, such as iron salts and aluminum salts, have a low cost, but they are highly dependent on temperature, $\mathrm{pH}$, and other conditions. Besides, for flocculation based on inorganic coagulants, the dosage is large and the suitable types of sewage are few (Sharma et al. 2006). In addition, it may cause the phenomenon of high metal concentration (Renault et al. 2009a) in the treated water body, and then threaten human health. Besides, organic flocculants can be divided into synthetic organic flocculants and biopolymer-based flocculants. The synthetic organic flocculants can reach good efficiency at low dosage, but have the risk of difficult biodegradability (Chen et al. 2018b) and toxicity ( $\mathrm{Lu}$ et al. 2014). Biopolymer-based flocculants refer to the long-chain molecules produced by the cells of living organisms and the materials derived from these longchain molecules or bio-based monomers (Song et al. 2009; Yates and Barlow 2013). Biopolymer-based flocculants have many excellent properties, such as wide sources, easy modification and processing, environmental friendliness (low toxicity/non-toxicity, easy biodegradation), low dosage requirements, a wide range of adaptable $\mathrm{pH}$, good flocculation efficiency (Renault et al. 2009a; Jiang 2015; Filho et al. 2018; Liu et al. 2020), etc. As biopolymer-based flocculants are of great benefit to reduce the risk of water treatment, researches of new flocculants based on biopolymers are the focus of scholars in recent years.

Biopolymer-based flocculants have the potential to scale up practical applications. In terms of economic feasibility, a triangle evaluation model was established to evaluate the performance of biopolymer-based flocculants in wastewater treatment (Sun et al. 2020a, b). This triangular evaluation model includes three aspects: environmental impact, economic benefit, and energy consumption. The evaluation results showed that these three aspects are obviously influenced by the flocculant characteristics and flocculation conditions of biopolymer-based flocculants; by optimizing these two aspects of biopolymer-based flocculants, can biopolymerbased flocculants have a low environmental impact, low energy consumption, and high economic benefits. Another report shows that the cost of flocculation depends not only on the cost of flocculant itself, but also on the dosage; although the unit price of chitosan is three times higher than that of ferric chloride, the cost of chitosan ( $65 \$$ ton treated biomass) is lower than that of ferric chloride (87\$/ton treated biomass) when it is used in flocculation of Chlamydomonas (Lama et al. 2016). In terms of practical application, the materials based on Moringa oleifera have been widely used in developing countries (Beltrán-Heredia and Sánchez-Martín 2009; Baptista et al. 2015). In Egypt and Sudan, natural polypeptides produced from the seeds of Moringa oleifera have been used to produce drinking water. When Moringa oleifera is used in drinking water treatment, the consumption of it is $1 \mathrm{seed} / \mathrm{L}$ for slightly polluted water, and 2 seeds/L for water with poor quality (Foidl et al. 2001). Therefore, biopolymer-based flocculants have the economic feasibility potential to scale up, which makes them likely to be widely used in the future.

However, at present, there are few reviews on biopolymerbased flocculants, while most of these reviews are only focused on chitosan. For example, Renault et al. (2009b) reviewed the flocculation efficiency of chitosan-based flocculants, and discussed the influence of chitosan characteristics and sewage conditions. Bhalkaran and Wilson (2016) also summarized the influence of sewage conditions on the treatment efficiency of chitosan-based flocculants. More importantly, they began to pay attention to the relationship between the physicochemical properties of flocculants and the wastewater treatment efficiency, namely the structurefunction relationship. Likewise, Yang et al. (2016a) reviewed the structural factors' effects on flocculation efficiency, and believed that they should be the focus of flocculants selection and design. Nevertheless, in addition to chitosan, there are many other biopolymers, such as starch, cellulose, and lignin etc. that can be used as the base materials of biopolymer-based flocculants. Being similar to chitosan, they also have the advantages of non-toxicity, environmental friendliness, and biodegradability. Therefore, an overview of the various biopolymers is necessary.

The flocculation efficiency of biopolymer-based flocculants is affected by their physicochemical properties (Bhalkaran and Wilson 2016). These characteristics are produced by the modification of biopolymers. Tang et al. (2018) summarized the factors influencing the preparation of biopolymer-based flocculants by graft polymerization. However, with the recent development, there are many modification methods to prepare biopolymer-based flocculants from natural raw materials, not only by graft polymerization. Thus, it is essential to summarize the modification methods of biopolymer-based flocculants, according to the reaction types.

Some of the flocculation mechanisms for biopolymerbased flocculants are similar to those of inorganic coagulants and synthetic organic flocculants, but it has something unique. Lee et al. (2014) believed that the flocculation mechanisms of biopolymer-based flocculants are mainly charge attraction, charge neutralization, and bridging. From recent reports, some novel interactions between biopolymer-based flocculants and contaminants have been reported. In order to have a comprehensive understanding for the flocculation mechanisms of biopolymer-based flocculants, it is necessary to review the interaction between biopolymer-based flocculants and various contaminants from the latest researches.

Accordingly, in this paper, the commonly used base materials, modification methods (according to reaction types), flocculation mechanisms, and water treatment applications of biopolymer-based flocculants are reviewed. At the same time, 
the future perspectives of biopolymer-based flocculants are discussed. Firstly, according to the sources and extraction methods of the base materials, it is obviously known whether their natural reserves are rich and whether they are economical and easy to obtain. Therefore, the sources of the base materials and the new biopolymer-based flocculants researches based on these materials in recent years are summarized. Secondly, at present, there are few reports summarizing the modification methods of biopolymer-based flocculants according to reaction types. However, the modification methods of different reaction types affect the structural characteristics of flocculants, which may have an important impact on the flocculation effect (Yang et al. 2016a). Thus, according to the different reaction types, the modification methods of biopolymerbased flocculants are reviewed in detail. Thirdly, a deep understanding of flocculation mechanisms is conducive to the further design of biopolymer-based flocculants. Nevertheless, a comprehensive summary about this is lacking. Therefore, the flocculation mechanisms of the biopolymer-based flocculants are systematically studied in this paper. Fourthly, the water treatment conditions, the removal efficiency and advantages of biopolymer-based flocculants in applications are summarized. Finally, the future development of biopolymer-based flocculants is prospected. This review aims to provide a reference for the development of biopolymer-based flocculants with higher efficiency, a lower cost, more safety, and multifunction in the future.

\section{Progress in the commonly used base materials}

The base materials which are biopolymers extracted from natural raw materials are diversified and rich in reserves. They can be obtained from animals, plants, and fungi etc. At present, among the diverse base materials used in the researches of biopolymer-based flocculants, the commonly used are chitosan, starch, cellulose, and lignin.

\section{Chitosan}

Chitosan is a kind of polycationic polysaccharide with a low cost and wide sources (Zheng et al. 2018). It has the properties of biodegradability, immunostimulatory, and antibacterial activity (Sanchez-Salvador et al. 2021). Chitosan can be obtained by partial deacetylation of chitin. This process of chitin requires high-temperature chemical hydrolysis in concentrated alkaline solution (Duan et al. 2019). In recent reports, the sources of chitosan were Rhizopus oryzae NRRL1526 (Sebastian et al. 2019), Zophobas morio larvae (Soon et al. 2018), prawn shells (Muley et al. 2018), shrimp shells (Tolesa et al. 2019), and blue crab shells (Lee et al. 2018), (Table 1) etc. The process of extracting chitosan from natural raw materials mainly includes three steps: demineralization, deproteinization, and deacetylation. At present, the most common commercial extraction method of chitosan is the chemical method using strong acids and bases. In order to reduce the reaction time and improve the purity and yield of the product, researchers have developed many new extraction methods of chitosan. Among them, the microwave radiation assistant extraction method has been widely used (El Knidri et al. 2018). After extraction, chitosan with $90 \%$ deacetylation for water treatment was about 30-40 \$/kg (Varlamov and Mysyakina 2018). Besides, there are amino and hydroxyl groups in the chitosan molecular structure (Table 1), easy for modification that makes it possible for chitosan to obtain multi-function and more chemical properties (Filho et al. 2018). Some properties (mechanical and structural properties, solubility and gel formation ability) of chitosan can be changed by incorporating to the new copolymers (Sanchez-Salvador et al. 2021). Therefore, chitosan is a kind of good base material for biopolymer-based flocculants.

\section{Starch}

Starch, a polymer composed of $\alpha$-D-glucose units (Bolto and Gregory 2007b), is a kind of water-soluble glycan with strong regeneration (Wei et al. 2018b). In recent reports, the natural sources of starch are as follows: Mango kernels (Ferraz et al. 2019), Green seaweed Ulva ohnoi (Prabhu et al. 2019), Yellow Skin Potatos (Altemimi 2018), Yam tuber (Dioscorea bulbifera) (Bernardo et al. 2018), Arrowroot rhizomes (Maranta arundinaceae L.) (Nogueira et al. 2018) (Table 1) etc. The common methods for extracting starch are the wet milling process and the alkali method from cereals as the largest source (El Halal et al. 2019). Starch has the advantages of low price and easy availability, due to its abundance. In 2016, the price of starch in the market was $1.6 \$ / \mathrm{kg}$ (Tesfaye et al. 2018). Based on the above advantages, the development of starch as a biopolymer-based flocculant started very early (Fanta et al. 1972).

\section{Cellulose}

Cellulose is the most abundant biopolymer in the world. Its structure consists of repeated covalently linked $\beta$-Danhydroglucopyranose units (Roy et al. 2009). In recent researches, the sources of cellulose are Rose stems (Rosa spp.) (Ventura-Cruz and Tecante 2019), Citrullus colocynthis seeds (Kouadri and Satha 2018), Sugarcane bagasse (Feng et al. 2018), Napier grass stems (Reddy et al. 2018), Posidonia oceanica brown algae (Tarchoun et al. 2019), Banana peel, and bract (Harini et al. 2018) (Table 1) etc. Because of its abundant sources, the price of cellulose is very low. Some researchers estimated that the price of cellulose was about $0.40 € / \mathrm{kg}$ (Abels et al. 2013), that is, about $0.47 \$ / \mathrm{kg}$. 
Table 1 Sources of biopolymer-based flocculants

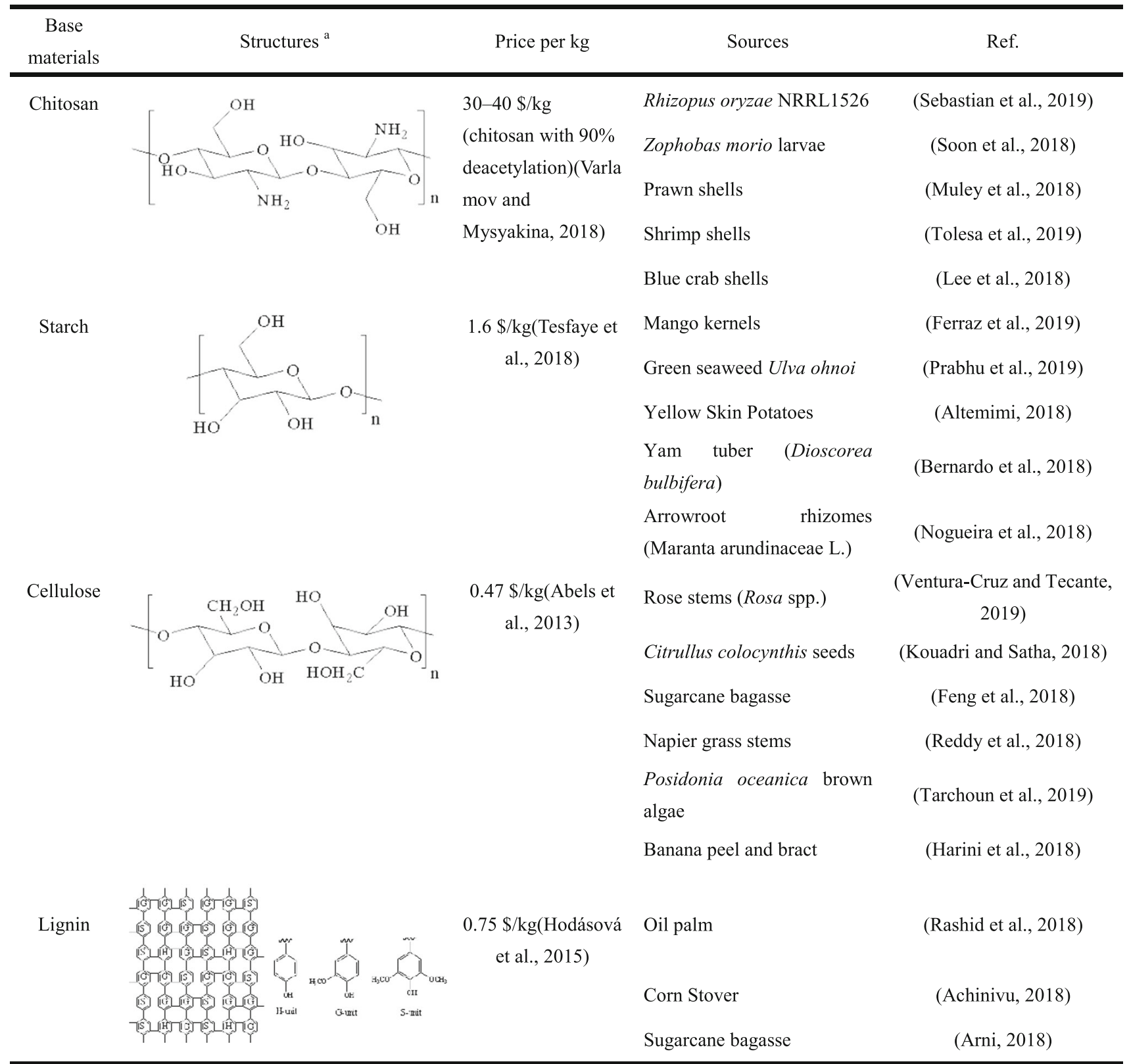

a The structures of chitosan and starch are redrawn from Salehizadeh et al. (2018) Recent advances in polysaccharide bio-based flocculants. Biotechnol. $A d v$. 2018. The structures of cellulose and lignin are redrawn from Chio et al. (2019) Lignin utilization: A review of lignin depolymerization from various aspects. Renew. Sust. Energ. Rev. 2019

Therefore, a lot of researches have been devoted to the chemical modification of cellulose to improve its water solubility and flocculation performance for better application in water treatment (Cai et al. 2015). In 2002, cellulose was successfully dissolved by some ionic liquids for the first time. Since then, many cellulose-based materials have been prepared by using ionic liquids as direct solvents and dissolution regeneration process (Xia et al. 2020).

Nanocellulose has attracted some researchers' attention due to its high specific surface area, high tensile strength, high reactivity, and low density (Morantes et al. 2019; Negro et al. 2020). Therefore, some studies used nanocellulose as flocculants. For example, cationic hairy cellulose nanocrystals can flocculate clay suspension in a wide dosage range $(7.5-75 \mathrm{mg} /$ g) (Campano et al. 2019b). Morantes et al. (2019) used epoxypropyltrimethylammonium chloride to react with cellulose nanocrystals. By this method, they prepared a cationic cellulose-based flocculant (CNC-EPTMAC), which was used to treat 0.25 wt. $\% \mathrm{SiO}_{2}$ suspensions. The results showed that the reduction of the $\mathrm{SiO}_{2}$ concentration in 
suspension could be $99.7 \%$ when the concentration of CNC-EPTMAC was only $2 \mathrm{ppm}$. It seems that cellulose nanocrystals with a small size could be a good choice to synthesize cellulose-based flocculants.

\section{Lignin}

Lignin, a biopolymer with the second largest nature reserves in the world (Brenelli et al. 2016), has a variety of functional groups, such as carbonyl, carboxyl, phenolic hydroxyl, alcohol hydroxyl, aromatic, methoxy, and conjugated double bond (Guo et al. 2018b) etc. In recent reports, the sources of lignin are as follows: Oil palm (Rashid et al. 2018), Corn Stover (Achinivu 2018), Sugarcane bagasse (Arni 2018) (Table 1) etc. At present, the most commonly used method to extract cellulose from raw biomass is to decompose lignin into soluble segments, dissolve them in solvents, and then separate lignin from the filtrate (Jiang and $\mathrm{Hu}$ 2016). To dissolve lignin, many researchers try ionic liquids as solvents, which was inspired by the effectiveness of ionic liquids as strong solvents for cellulose. Dissolved in ionic liquids, lignin can be depolymerized to further produce ligninderived materials. The depolymerization methods include acid depolymerization, alkali depolymerization, hydrogenation depolymerization, and oxidation depolymerization. In addition, lignin can also be transformed into a series of derivative materials with ionic liquids as solvents and additives (Xia et al. 2020). After it is extracted from the natural sources, the price of high purity lignin could be $0.75 \$ / \mathrm{kg}$ (Hodásová et al. 2015). Besides, lignin is abundant in paper mill sludge, making it a potential source of lignin. Making use of paper mill sludge, a kind of waste, to prepare water purification materials, in turn to solve environmental problems, will be of great value (Guo et al. 2018b).

In the past, the preparation methods of lignin-based flocculants in many researches were based on free radical polymerization. However, lignin will inhibit the free radical reaction and reduce the grafting efficiency in free radical polymerization-based preparation methods. To solve this problem, Chen et al. (2020a) developed a new grafting method. In their study, linear cationic polyacrylamide was synthesized by free radical polymerization, using 4-chloromethyl styrene as a chain transfer agent, ammonium persulfate as an initiator, acrylamide, and methylacryloyloxyethyltrimethyl ammonium chloride as monomers. Then, the lignin-cationic polyacrylamide flocculant was prepared by the mixing reaction of cationic polyacrylamide, enzymatic hydrolysis lignin, and $\mathrm{NaOH}$ solution. The grafting efficiency was improved by the effective reaction of chlorine of cationic polyacrylamide with phenolic hydroxyl groups of lignin.

\section{Some other base materials}

In addition to the above four main materials, researchers also used a variety of other biopolymers for the synthesis of biopolymer-based flocculants. For example, Moringa oleifera-based flocculants are easily operated by unqualified persons, and the water treated by Moringa oleifera based flocculants has little impact on human health. Therefore, this kind of material is favored by developing countries (BeltránHeredia and Sánchez-Martín 2009). Furthermore, it has been reported that a coagulant was extracted from Moringa oleifera by the method of saline and aqueous extraction processes followed by ultrafiltration. This coagulant can reduce the pollutant concentration of surface water without increasing the organic matter in the treated water (Baptista et al. 2015).

Agricultural production will generate a large number of non-food biomass. Although the utilization rate of these agricultural wastes is very low, they have considerable potential values (Goodman 2020). Therefore, using agricultural wastes to produce flocculants might be an attractive alternative strategy. For example, Khiari et al. have prepared sodium carboxymethyl cellulose flocculants with date palm rachis, an agricultural waste, as raw materials, and investigated its turbidity removal efficiency. The results show that under the optimal conditions, the turbidity removal rate of the flocculant produced by date palm rachis was about $95 \%$ (Khiari et al. 2010). Besides, some researchers extracted mucilage from the peel of dragon fruit, and used it with polyaluminum chloride for turbidity removal. The results show that this kind of mucilage can reduce the dosage of polyaluminum chloride, and improve the removal rate of turbidity (Le et al. 2020).

Extracellular biopolymer flocculants (EBFs) are substances secreted by a variety of microorganisms in a culture medium. These substances are composed of proteins, polysaccharides, and lipids. EBFs are nontoxic and biodegradable (Salehizadeh and Yan 2014). For example, Paenibacillus elgii B69 can produce an exopolysaccharide compound of gluconic acid, glucose, mannose, and xylose. This kind of EBFs has good flocculation efficiency of dyes, kaolin, and heavy metal ions (Li et al. 2013). High polymer polysaccharide and protein, produced by Klebsiella sp., can remove $53.27 \%$ sulfamethoxazole from domestic water (Xing et al. 2013). In another research, Bacillus licheniformis cells and metabolites (protein and polysaccharide) were used to flocculate kaolin and quartz. The results showed that different metabolic components (protein and polysaccharide) had good efficiency on different target removal substances (kaolin and quartz), respectively (Ghashoghchi et al. 2017).

Besides, a kind of dextran-based flocculant was prepared and used in the wastewater treatment of a kaolin-Congo red binary contaminants system. The maximum removal rate of dextran-based flocculants for the Congo red could reach $88.2 \%$ (Zhao et al. 2018). A kind of $\beta$-cyclodextrin-based flocculant was synthesized by the ultrasound-assisted method. The turbidity removal rate of humic acid-kaolin sewage with the $\beta$-cyclodextrin-based flocculant could reach $97.5 \%$ (Liu et al. 2019). The residual turbidity of 3 mass $\%$ kaolin 
suspension treated with the poly (vinyl alcohol)-Acacia nilotica gum flocculant was as low as 15.3 NTU under the optimal conditions (Nasim et al. 2018). In addition, the xylanbased flocculant was used to treat pulp mill wastewater; the removal rates of turbidity and lignin were $94.5 \%$ and $45.0 \%$, respectively (Chen et al. 2018b).

\section{Development of the modification methods}

In order to further improve the flocculation performance of biopolymer-based flocculants, or to achieve the multifunctionality of flocculants (e.g., sterilization(Liu et al. 2017a; El-Naggar et al. 2018; Li et al. 2017; Chen et al. 2020b; Tang et al. 2010), scale-inhibition (Du et al. 2018b)), researchers would like to modify various functional groups on biopolymers. Through the modification of different reaction types, biopolymers may get different structural characteristics (functional groups, molecular weight, charge density, etc.). As a result, the molecular structure of biopolymer-based flocculants seems to impact the flocculation efficiency (Yang et al. 2016a). Therefore, the selection of modification methods is the key to preparing biopolymer-based flocculants, but there are few reports summarizing the modification methods according to different reaction types. In this part, they are summarized according to reaction types, such as graft copolymerization, etherification, amination, esterification, acylation, oxidation, cross-linking, and Mannich reaction, as shown in Table 2.

\section{Graft copolymerization}

Graft copolymerization of biopolymer-based flocculants can be initiated in many ways, including thermal initiation, photo initiation, radiation initiation, microwave initiation, and plasma initiation.

\section{Thermal initiation}

Heating monomers to produce free radicals can cause polymerization. However, the activity of monomers is usually low, so initiators are often added to solve this problem. The initiator decomposes to produce free radicals by heating, which can further initiate polymerization. Initiator VA-044 in the thermal initiation method was reported by Liu et al. (2018a). In their experiments, magnetic nanoparticles were firstly prepared by solvothermal method, and then modified by vinyl groups; finally, the VA-044 initiator was used to initiate graft copolymerization of itaconic acid, chitosan, and the modified magnetic nanoparticles at $50{ }^{\circ} \mathrm{C}$ to prepare the magnetic flocculant Mag@PIA-g-CS.

Among these initiation methods, the reaction efficiency of thermal initiation may be the lowest (Zhao et al. 2018). Mishra and Kundu (2019) compared the characteristics of the biopolymer-based flocculants prepared by microwave initiation with those by thermal initiation. In that study, polyacrylamide grafted-fenugreek gum was prepared by microwave initiation and thermal initiation (Table 2), respectively, using fenugreek gum as a base material, ceric ammonium nitrate as an initiator, and acrylamide as a graft monomer. The flocculation experiments demonstrated that the turbidity removal rate of the biopolymer-based flocculants prepared by microwave irradiation was about $96 \%$, while that by the thermal initiation was $89 \%$. Therefore, it could be concluded that thermal initiation may be not a good way to initiate graft copolymerization.

Photo initiation The polymerization of monomers with biopolymers can be initiated under UV irradiation. It has been reported that the CS-g-pAO flocculant was prepared under $500 \mathrm{~W}$ and $11.7 \times 10^{2} \mu \mathrm{w} / \mathrm{cm}^{2}$ of UV irradiation by grafting acryloyloxyethyl dimethylbenzyl ammonium chloride and acrylamide onto chitosan with VA-044 as a photo initiator (Liu et al. 2020) (Table 2). Similarly, another study (Liu et al. 2018b) polymerized acrylamide, itaconic acid, and chitosan to obtain the CS-g-p (AM-IA) flocculant by UV initiation, namely photo initiation.

Radiation initiation Radiation initiation refers to the polymerization of each reactant initiated under the irradiation of high-energy rays (e.g., $\alpha$-ray, $\beta$-ray, $\gamma$-ray, $X$-ray, etc.). For example, under $\gamma$-ray initiated copolymerization, acrylamide and (2-methacryloyloxyethyl) trimethyl ammonium chloride were grafted onto chitosan (Wang et al. 2012) (Table 2).

Microwave initiation The microwave frequency of $2450 \pm$ $50 \mathrm{MHz}$ is close to the rotational vibration frequency of the chemical groups, which can activate the groups and make the monomers polymerized. Under the microwave of $2450 \mathrm{MHz}$, Wu et al. (2020) synthesized the CS-g-pAD flocculant by grafting acryloyloxyethyl trimethylammonium chloride and acrylamide onto chitosan (Table 2).

Plasma initiation When ionized gaseous substances, composed of electrons, ions and neutral particles, irradiate monomers, monomer polymerization occurs as a result. Through plasma initiation, Sun et al. (2017) synthesized acrylamide-diallyldimethylammonium chloride-graftedchitosan under certain discharge power and reaction time (Table 2).

\section{Etherification}

As shown in Table 1, biopolymers contain abundant hydroxyl groups, making the materials easily etherified with etherifying agents under alkaline conditions. Wang et al. (2016b) 
Table 2 Reaction types of modification in biopolymer-based flocculants synthesis processes

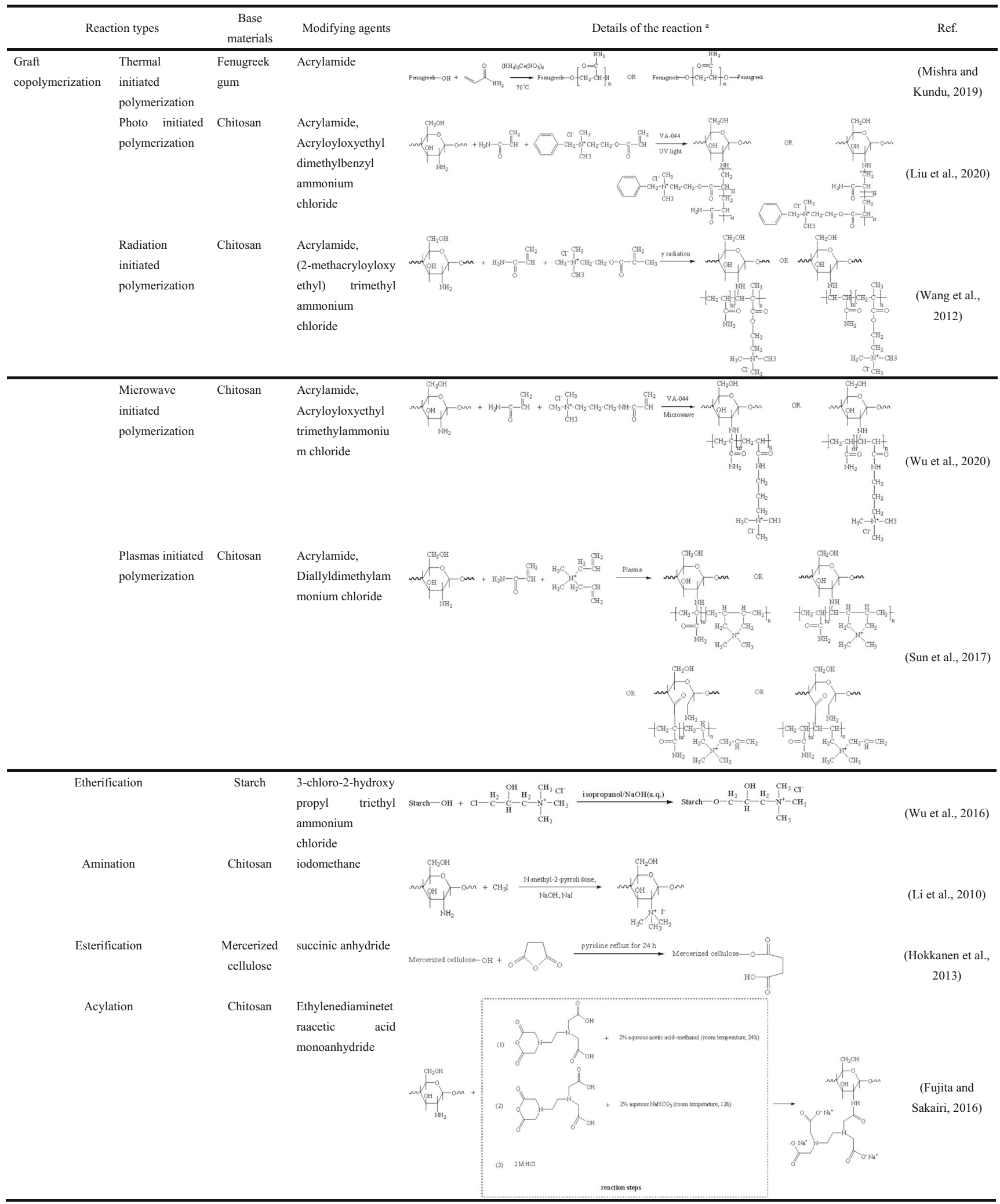




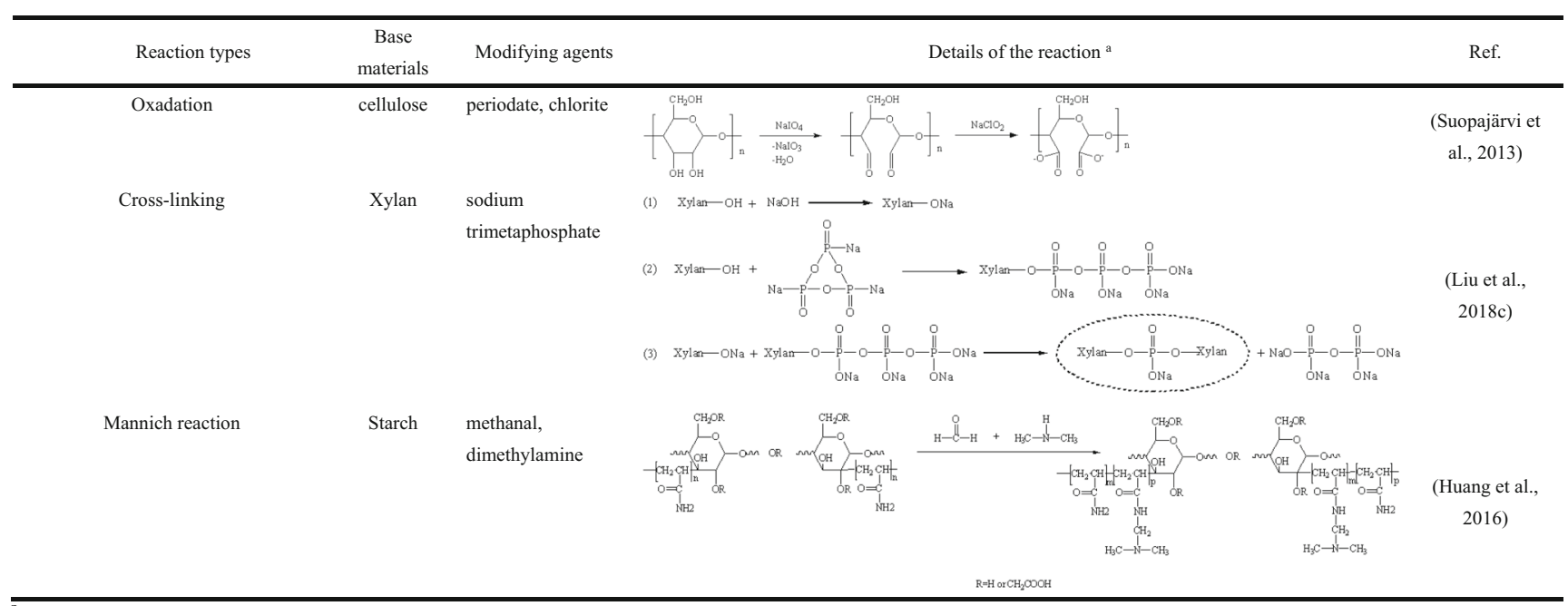

${ }^{\mathrm{a}}$ Partial steps from the synthesis processes

etherified water-soluble starch with butyl glycidyl ether. Firstly, 2-hydroxy-3-butoxypropyl starch was formed. Then, in the dimethyl sulfoxide solvent, the cationic etherifying agent 2,4-bis(dimethylamino)-6-chloro-[1,3,5]-triazine was used to etherify 2-hydroxy-3-butoxypropyl starch to form temperature \& $\mathrm{pH}$ responsive starch. Three starch-based flocculants were prepared by $\mathrm{Wu}$ et al. (2016), among which etherification was used in the modification of two flocculants (STC-CTA and CMS-g-PDMC). STC-CTA was prepared by the etherification of starch with (3-chloro-2-hydroxypropyl) trimethyl ammonium chloride (Table 2). In the preparation of CMS-g-PDMC, chloroacetic acid was used as an etherifying agent which reacted with starch to prepare carboxymethyl starch, and then poly [ (2methacryloyloxyethyl) trimethyl ammonium chloride] was grafted to carboxymethyl starch under the initiation of potassium persulfate.

\section{Amination}

Amination is a common and simple method for preparing biopolymer-based flocculants (Yang et al. 2016a). Li et al. (2010) synthesized N,N,N-trimethyl chitosan chloride through the reductive methylation of chitosan and iodomethane, which was called a special direct amination (Yang et al. 2016a) (Table 2). After that, an amphiphilic chitosan-based flocculant (O-carboxymethyl-N-trimethyl chitosan chloride) was synthesized by reductive carboxymethylation of N,N,N-trimethyl chitosan chloride with monochloroacetic acid in the presence of sodium hydroxide.

\section{Esterification}

The hydroxyl groups on biopolymers can be converted into ester groups after esterification with organic and inorganic acids and their derivatives (e.g., anhydride, chloride and oxychloride) (Lewicka et al. 2015). As can be seen in Table 2, Hokkanen et al. (2013) esterified mercerized cellulose with succinic anhydride to form a cellulose-based flocculant under pyridine reflux.

\section{Acylation}

Acylation introduces acyl groups into the nitrogen and oxygen etcetera atoms of biopolymers. Parviainen et al. (2014) directly acylated the hydroxyl groups of cellulose with 2bromoisobutyryl bromide to obtain a cellulose macromolecular initiator. Then, N,N-dimethyl aminoethyl methacrylate was grafted with the macromolecular initiator to form cellulose-g-poly(N,N-dimethyl aminoethyl methacrylate). Finally, it was quaternized to form cellulose-g-poly(methacryloxyethyl trimethylammonium chloride). In another research (Fujita and Sakairi 2016) (Table 2), ethylene diamine tetraacetic acid-linked chitosan was synthesized by $\mathrm{N}$ acylation of chitosan and ethylene diamine tetraacetic acid monoanhydride. This flocculant is a linear non-crosslinking polymer.

\section{Oxidation}

The hydroxyl groups on biopolymers can be oxidized to aldehyde groups. In addition, the aldehyde groups can be further transformed into other functional groups by modification. Suopajärvi et al. (2013) used sodium periodate to oxidize the two ortho hydroxyl groups in cellulose to form aldehyde groups, and then used sodium chlorite to oxidize aldehyde groups to carboxyl groups, thus introducing dicarboxyl groups into cellulose (Table 2). 


\section{Cross-linking}

The molecular weight of biopolymers can be increased by cross-linking modification. The increase of molecular weight can improve the bridging flocculation efficiency of biopolymer-based flocculants (Runkana et al. 2006). Thus, cross-linking may be a good method to enhance the flocculation efficiency of biopolymer-based flocculants. As shown in Table 2, Liu et al. (2018c) applied a reported cross-linking method (Dulong et al. 2004) to prepare biopolymer-based flocculants. They used sodium trimetaphosphate as a crosslinking agent to make xylan cross-linked in an alkaline condition to form the phosphorylated xylan flocculant.

\section{Mannich reaction}

Mannich reaction was reported in 1912 (Mannich and Krösche 1912). This method was also used in the modification of biopolymer-based flocculants. Huang et al. (2016) carboxymethylated starch with monochloroacetic acid to form carboxymethyl starch. Then, acrylamide monomer was grafted onto carboxymethyl starch by the initiation of ammonium persulfate to obtain CMS-g-PAM. Finally, CMS-gPAM was added into the aqueous solution of formaldehyde and dimethylamine for Mannich reaction to obtain carboxymethyl-starch-graft-aminomethylatedpolyacrylamide (Table 2).

\section{Flocculation mechanisms of biopolymer-based flocculants}

Generally, the principle of flocculation lies in the solid-liquid separation of sewage or sludge. Like other kinds of flocculants, biopolymer-based flocculants can destabilize, aggregate, and separate (e.g., ordinary sedimentation (Li et al. 2018) and magnetic separation (Lü et al. 2018; Liu et al. 2018a)) aqueous contaminants by destroying the stability of the colloidal system in polluted water. However, according to the recent researches, there is something special about the flocculation mechanisms of biopolymer-based flocculants. In general, the flocculation process of biopolymer-based flocculants is usually the result of several mechanisms, including adsorption, bridging, charge neutralization, net trapping and sweeping, as well as, some other special mechanisms. In detail, some case studies are listed in Table 3.

\section{Adsorption mechanism}

There are usually charge attraction (Zeng et al. 2019; Jia et al. 2016; Yang et al. 2016b; Li et al. 2018) and hydrogen bond (Ren et al. 2017) between the molecular chain of biopolymer- based flocculants and the surface of contaminants, which will result in the adsorption of contaminants onto the biopolymerbased flocculants molecules. When the charges carried by biopolymer-based flocculants molecules and contaminants are opposite, adsorption occurs between them, which is referred to as charge attraction; Hydrogen bond refers to the adsorption between contaminants and biopolymer-based flocculants by the attraction of hydrogen atoms and electronegative atoms. Thus, the adsorption occurs in effective attached sites, not in the whole molecular chain (Sharma et al. 2006). As shown in Figure 1, the detached sites of biopolymer-based flocculants would extend into the water.

Compared with unmodified biopolymers, the biopolymerbased flocculants usually gain longer molecular chains and higher molecular weight through modification. Thus, the probability of effective attached sites in biopolymer-based flocculants may be higher, allowing biopolymer-based flocculants to absorb more contaminants (Wu et al. 2020).

\section{Bridging mechanism}

After the effective attached sites on the biopolymer-based flocculants adsorb the contaminants, the non-adsorbed parts of the chain will extend to the outside, like "bridging," adsorbing, and linking other more contaminants (Figure 2a). This phenomenon of bridging the long-distance contaminants into flocs is called the bridging mechanism. It is common in biopolymer-based flocculants (Zeng et al. 2019; Guo et al. 2018b, 2019; Li et al. 2018; Lü et al. 2019; Chen et al. 2018b; Sun et al. 2020b; Wu et al. 2020).

In the case of bridging flocculation, the higher molecular weight of the biopolymer-based flocculants is, the higher flocculation efficiency will be (Runkana et al. 2006). However, the effects of dosage may be more varied. When the dosage of biopolymer-based flocculants is excessive (Figure $2 b$ ), the surface of contaminants is totally covered by biopolymerbased flocculants molecules, and there will be no site on the contaminants to bridge. Consequently, the aqueous system becomes stabilized, and the flocculation efficiency deteriorates (Sun et al. 2020b). Nonetheless, when the dosage of biopolymer-based flocculants is inadequate (Figure 2c), there may be no enough effective bridge contact (Bolto and Gregory 2007b).

\section{Charge neutralization mechanism}

The contaminants in sewage usually have the same charges. Therefore, the electrostatic repulsion between them makes them disperse uniformly and stably in the colloidal system, which is not easy to agglomerate. If the electrical property of the biopolymer-based flocculants is opposite to that of the contaminants, the electrostatic attraction makes the biopolymer-based flocculants molecules be adsorbed on the 


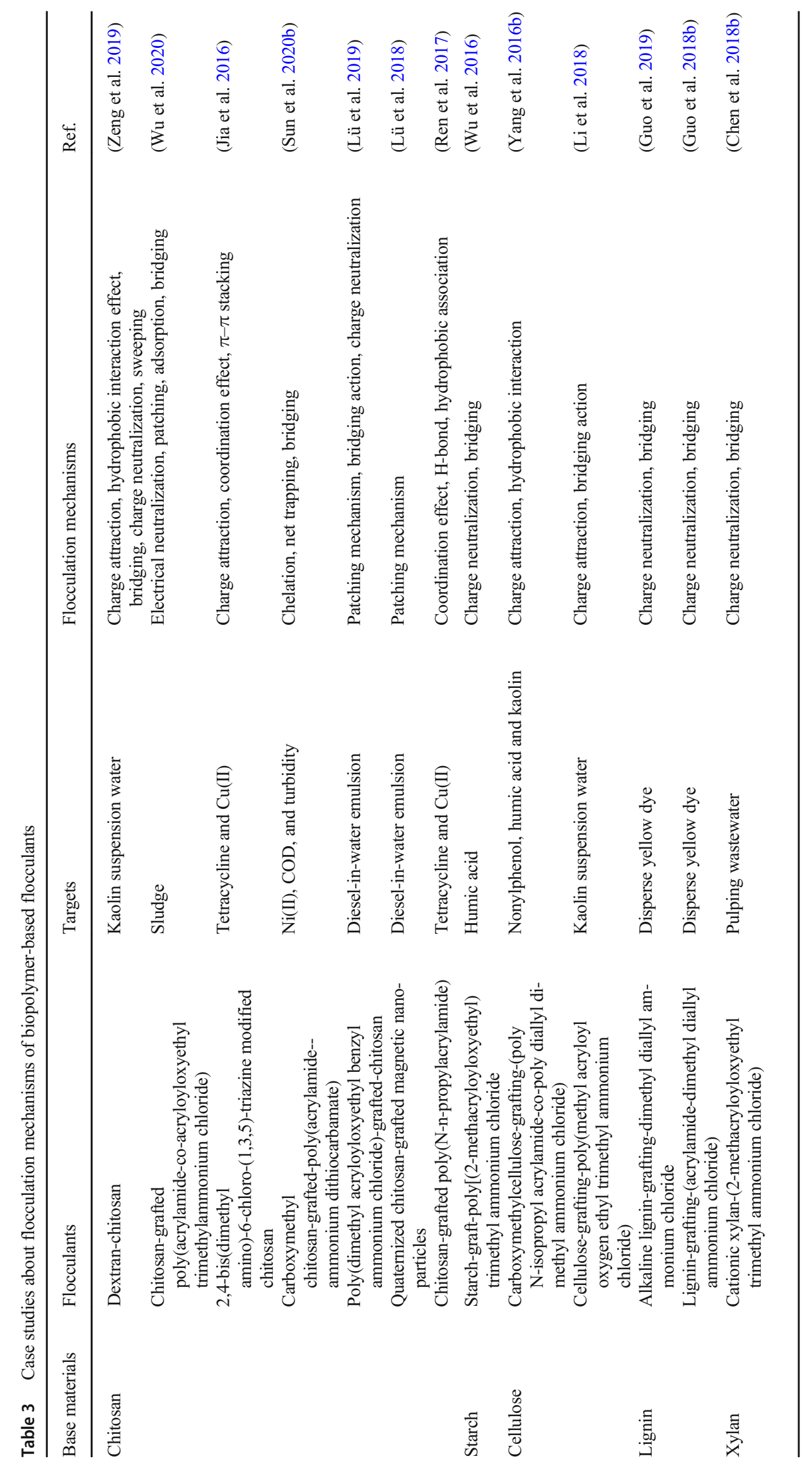




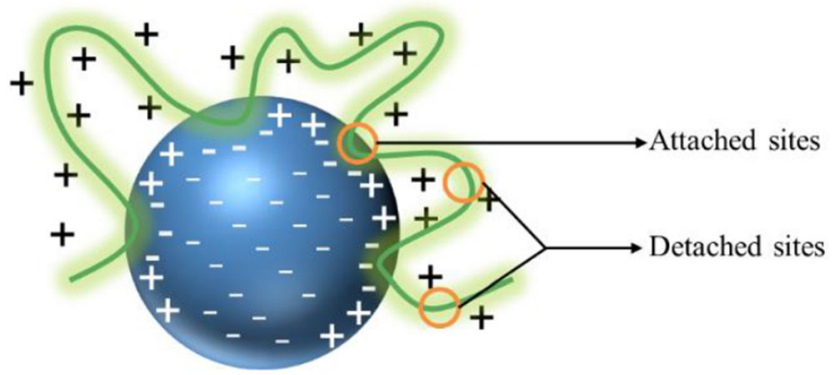

Fig. 1 Adsorption mechanism (Sharma et al. 2006) of biopolymer-based flocculants

surface of contaminants, resulting in charge neutralization. It decreases the electric repulsion between contaminants. Then, contaminants will collide with each other under the Brownian motion, which leads to flocculation (Zeng et al. 2019; Guo et al. 2019; Guo et al. 2018b; Chen et al. 2018b; Wu et al. 2020). This phenomenon is called charge neutralization mechanism of biopolymer-based flocculants (Figure 3a). In addition, the mechanism of flocculation can be judged by measuring zeta potential. If the zeta potential of the system is close to 0 at the best flocculation efficiency point, the flocculation is mainly caused by charge neutralization (Lü et al. 2019).

However, there is another case. When the high charge density biopolymer-based flocculants are adsorbed on the surface of low charge density contaminants with opposite charges, sites on the

Fig. 2 Bridging mechanism of biopolymer-based flocculants; a Appropriate flocculants dosage (Bolto and Gregory 2007a), b excessive flocculants dosage, and c inadequate flocculants dosage surface of the contaminants may not be all neutralized by the molecular chain segments of biopolymer-based flocculants. The reason is that the sites may tend to be electrically neutral as a whole. Therefore, coating patches and uncoated regions with opposite electric charges are interspersed on the surface of contaminants. When contaminants are close to each other, electrostatic attraction exists between coating patches and uncoated regions with opposite charges, and thus flocculation will occur (Figure 3b). This mechanism, which is different from the ordinary charge neutralization mechanism, is called "patching mechanism." It often occurs in the flocculation of biopolymer-based flocculants (Lü et al. 2018; Lü et al. 2019; Wu et al. 2020).

\section{Net trapping and sweeping}

Net trapping (Sun et al. 2020b) and sweeping (Zeng et al. 2019) were found in the flocculation of biopolymer-based flocculants. As shown in Figure 4, the sediment initially formed by biopolymer-based flocculants will move for a period before settling down. During this process, the sediment will capture more other contaminants and form larger flocs.

\section{Other special mechanisms}

In addition to the above mechanisms, due to the abundant special functional groups of biopolymer-based flocculants,

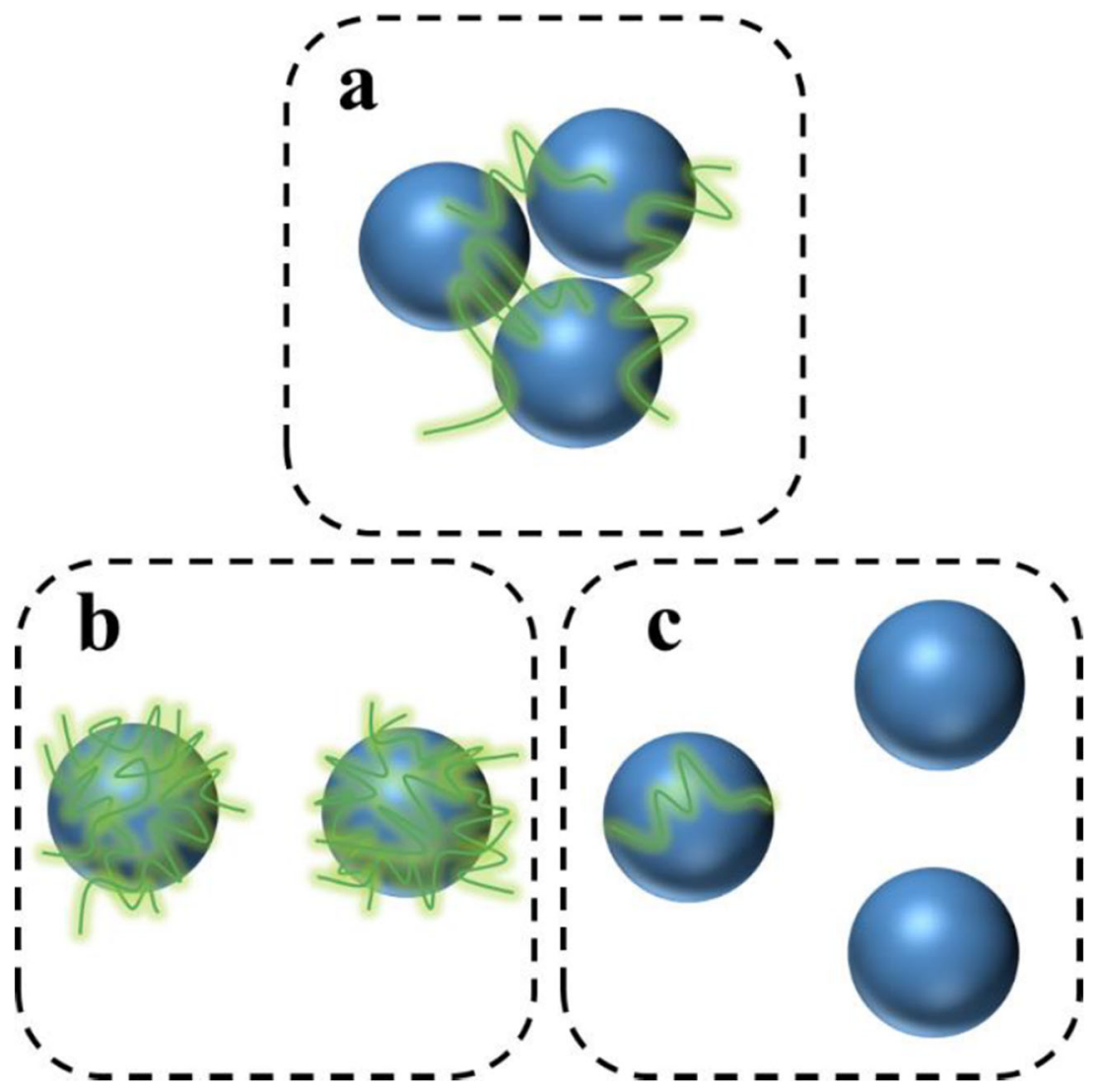


Fig. 3 Charge neutralization mechanism (Salehizadeh et al. 2018) of biopolymer-based flocculants: a Ordinary one; $\mathbf{b}$ Patching mechanism

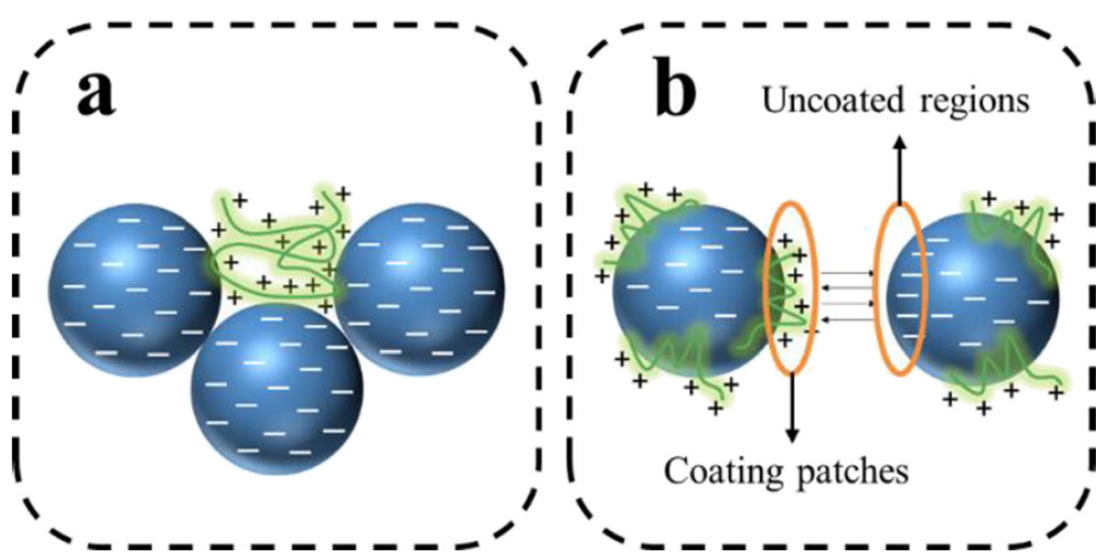

there are some other special mechanisms, such as hydrophobic interaction effect (Zeng et al. 2019; Yang et al. 2016b; Ren et al. 2017), coordination effect (Jia et al. 2016; Ren et al. 2017), chelation (Sun et al. 2020b; Tang et al. 2020), and $\pi-\pi$ stacking (Jia et al. 2016).

As shown in Figure 5, there are some case studies for the special flocculation mechanisms of biopolymer-based flocculants. (i) Hydrophobic interaction effect: the hydrophobic chains on the biopolymer-based flocculants will interact with hydrophobic contaminants. Then, the hydrophobic contaminants may be wrapped in the polymer net of biopolymer-based flocculants through the hydrophobic interaction (Yang et al. 2016b) (Figure 5a). (ii) Coordination effect: if the biopolymerbased flocculants contain amino, amide, hydroxyl groups etc., there will be coordination effect on heavy metal ions (Ren et al. 2017) (Figure 5b). (iii) Chelation: functional groups of biopolymer-based flocculants, such as carboxyl, dithiocarboxy groups etc., will form chelation with heavy metal ions (Sun et al. 2020b) (Figure 5c). (iv) $\pi-\pi$ stacking: if the aromatic rings are introduced into biopolymer-based flocculants through modification, the aromatic rings on biopolymerbased flocculants will react with the aromatic rings of contaminants by $\pi-\pi$ stacking(Jia et al. 2016) (Figure 5d).

As mentioned above, biopolymer-based flocculants, with rich functional groups, have varied flocculation mechanisms for contaminants. Thus, in applications, biopolymer-based

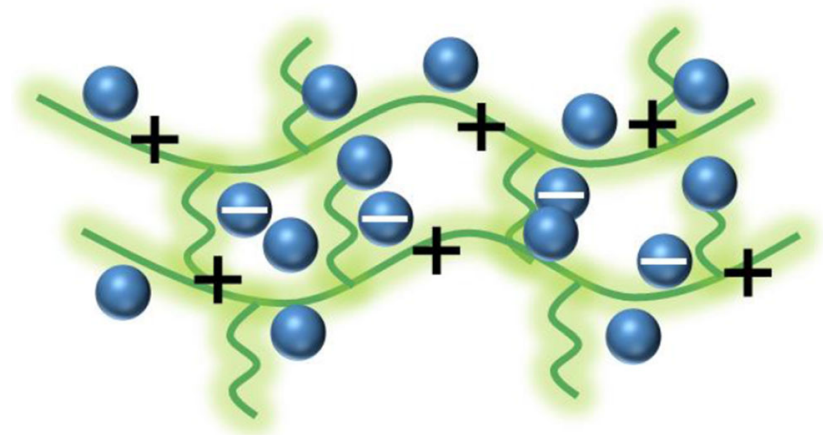

Fig. 4 Net trapping and sweeping mechanism of biopolymer-based flocculants (Zeng et al. 2019) flocculants may get satisfying flocculation efficiency by combined mechanisms.

\section{Recent applications of biopolymer-based flocculants}

Compared with the traditional flocculants, biopolymer-based flocculants, as a kind of newly born flocculants, their applications become more diversified. In recent years, biopolymerbased flocculants are mainly applied in the treatment of turbidity, dyes, heavy metal ions, and other industrial/ agricultural sewage, as well as algae capture and sludge dewatering. To reveal the parameter details, some case studies are listed in Table 4.

\section{Turbidity}

Most sewage usually contains a lot of fine suspended solids. If it is discharged into the environment, the turbidity of natural water will rise. As a result, it may cause adverse effects on the aquatic ecosystem (Wang et al. 2019b).

With the aid of biopolymer-based flocculants in the coagulation process for turbidity removal, the dosage of inorganic coagulants can be reduced. Thus, it can reduce the environmental risk and water treatment cost brought by inorganic coagulants. For example, a cellulose-based flocculant C-gPDMC (Li et al. 2018), which was prepared by methyl acryloyl oxygen ethyl trimethyl ammonium chloride grafted to microcrystalline cellulose, was used to treat kaolin suspension with polyaluminum chloride (PAC). The dosage of PAC was reduced with the aid of C-g-PDMC (optimal PAC dosage was $2 \mathrm{mg} / \mathrm{L}$ for single treatment and $1.5 \mathrm{mg} / \mathrm{L}$ for synergistic treatment). The removal rate of turbidity could reach $98.32 \%$ by the synergistic treatment of PAC and C-g-PDMC. Thus, biopolymer-based flocculants can be a good aid in reducing the dosage of inorganic coagulants.

Furthermore, when biopolymer-based flocculants are used alone in the turbidity flocculation, they present a high turbidity 
Fig. 5 Case studies for other flocculation mechanisms of biopolymer-based flocculants; a Hydrophobic interaction effect (Yang et al. 2016b), b coordination effect (Ren et al. 2017), c chelation (Sun et al. 2020b), and d $\pi-\pi$ stacking (Jia et al. 2016)

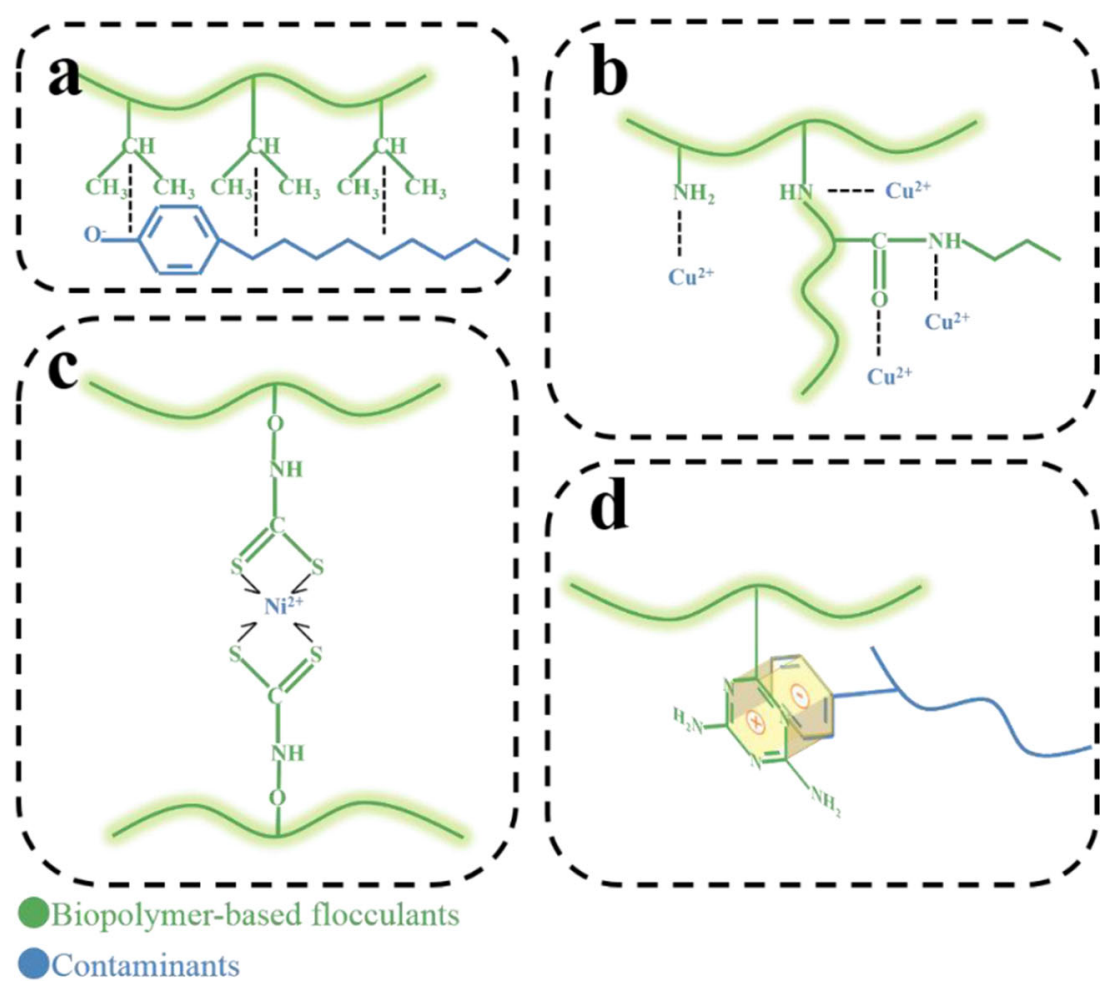

removal efficiency, a broad adaptable $\mathrm{pH}$ range, and resistance of the metal salts interference. (i) The high turbidity removal efficiency: in recent years, researches of biopolymer-based flocculants have greatly improved the turbidity removal efficiency, even more than $99 \%$. For example, the MCC(pAA-co-pDMC) flocculant was prepared by microcrystalline cellulose grafted with methacryloxyethyltrimethyl ammonium chloride and acrylic acid. The turbidity removal efficiency of it could reach $99.82 \%$ when $\mathrm{pH}$ was 7 and kaolin concentration was initially $5 \mathrm{~g} / \mathrm{L}$ (Wang et al. 2019b). The CMC-CTA flocculant, prepared by carboxymethyl chitosan grafted with 3-chloro-2-hydroxypropyl trimethylammonium chloride, got the highest turbidity removal rate of 99.2\%, at pH 4 (Agbovi and Wilson 2018). (ii) Wide adaptable $\mathrm{pH}$ range: It was reported that konjac g 1 u c o m a n n a n - g r a f t - p o l y - ( 2 methacryloyloxyethyl)trimethyl ammonium chloride had good turbidity removal efficiency on kaolin suspension in the range of $1<\mathrm{pH}<9$ (Ren et al. 2016). (iii) Resistance of metal salts interference: some biopolymerbased flocculants even get the optimum removal efficiency for turbidity with metal salt interference and under acidic conditions. For example, the PVA-NG flocculant (Nasim et al. 2018) was prepared by mixing polyvinyl alcohol and acacia nilotica gum. It had the optimum efficiency of treating 3 mass $\%$ kaolin suspension at the ratio of 7:3 (polyvinyl alcohol: acacia nilotica gum), dosage of $25 \mathrm{ppm}$, and $\mathrm{pH}$ of 2.6. The optimum residual turbidity is only 15.3 NTU. In addition, with the interference of
$0.03 \mathrm{M} \mathrm{Ca}^{2+}$ or $\mathrm{Fe}^{3+}$, the residual turbidity was even as low as 8.6 NTU and 10.52 NTU, respectively. Therefore, as an alternative to traditional flocculants, biopolymerbased flocculants can enhance turbidity removal efficiency with a wide adaptable $\mathrm{pH}$ range and good resistance of metal-salt interference.

It should be noted that some structural characteristics of biopolymer-based flocculants have a significant impact on turbidity removal. Liu et al. (2017b) prepared St-g-PAM-coPDMC with different charge densities and average graft chain lengths, by graft copolymerization of starch with different dosages of acrylamide and (2-methacryloyloxyethyl) trimethyl ammonium chloride. Then, the starch-based flocculants were used for the turbidity removal of the kaolin suspension. This study showed that high charge density could enhance the turbidity removal efficiency when the flocculant dosage was not sufficient; when the flocculant was excessive, high average graft chain length was easy to cause colloidal stabilization for Kaolin. Therefore, the expected treatment efficiency of turbidity could be obtained by designing the structural characteristic parameters such as charge density and average graft chain length of biopolymer-based flocculants.

\section{Dyes}

Sewage with dyes has a great negative impact on the ecological environment and human health. The reason is that the dye molecules have biological toxicity, and the toxicity can be further enhanced when the molecules chelate metal ions. 


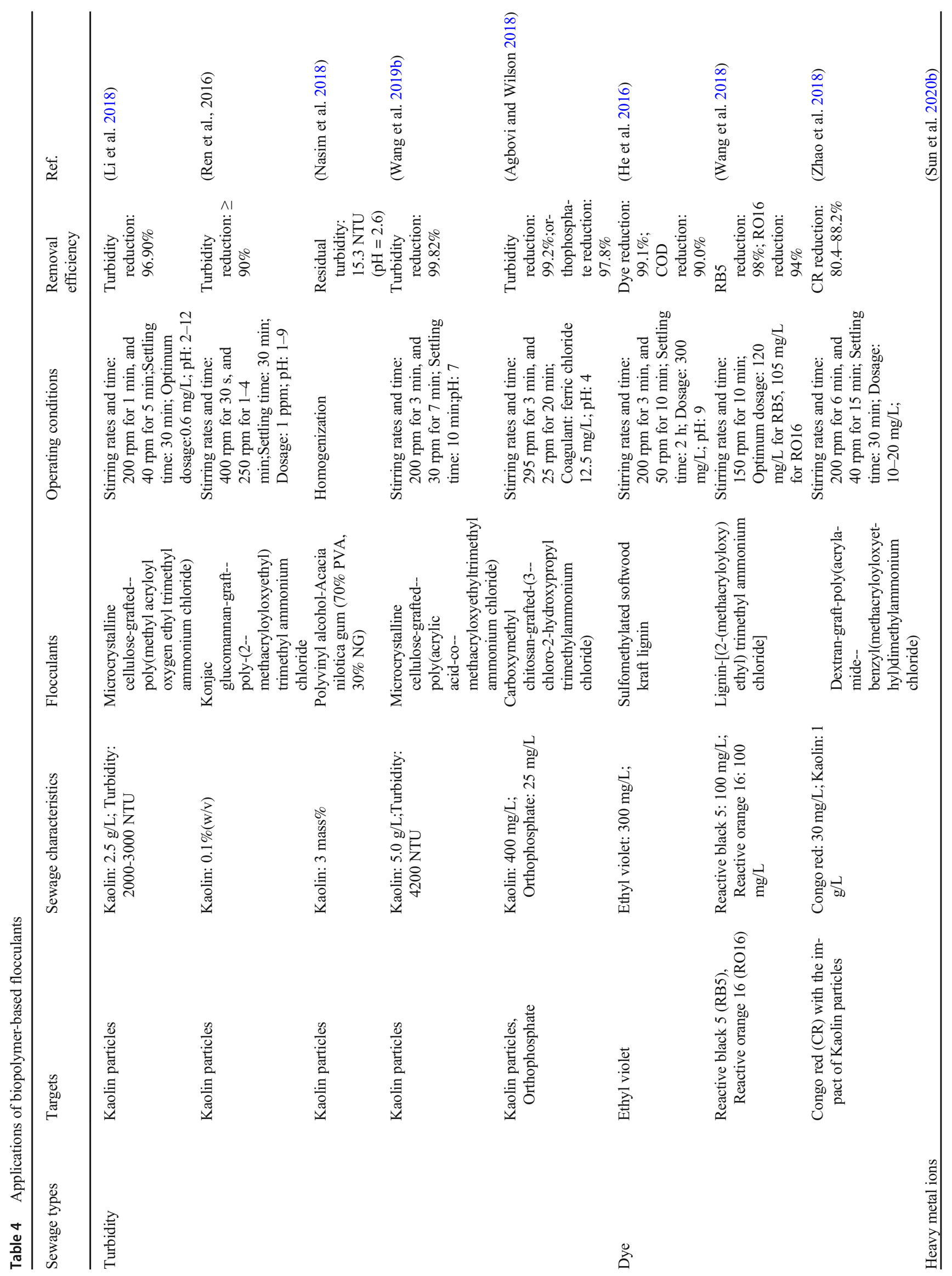




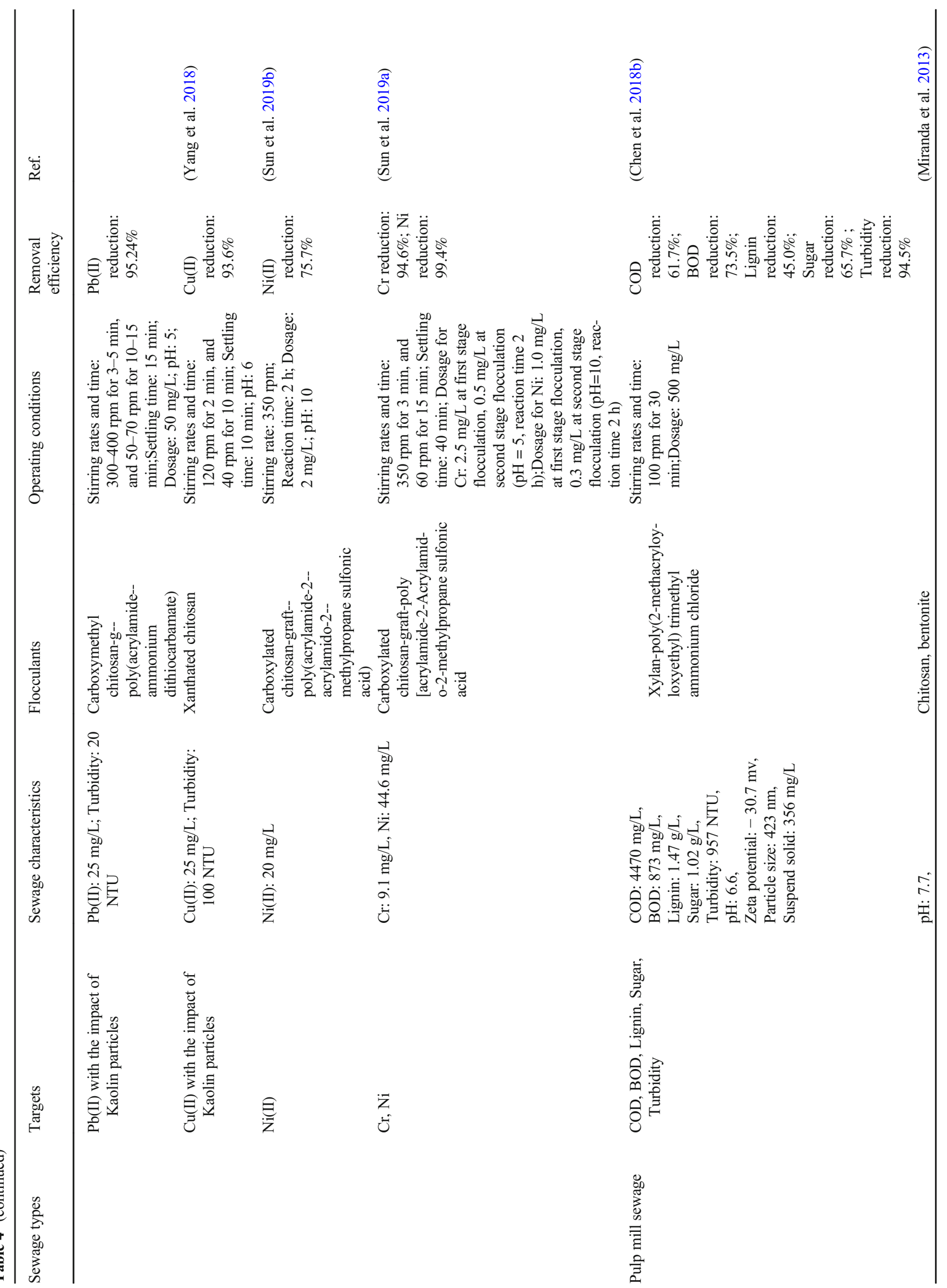




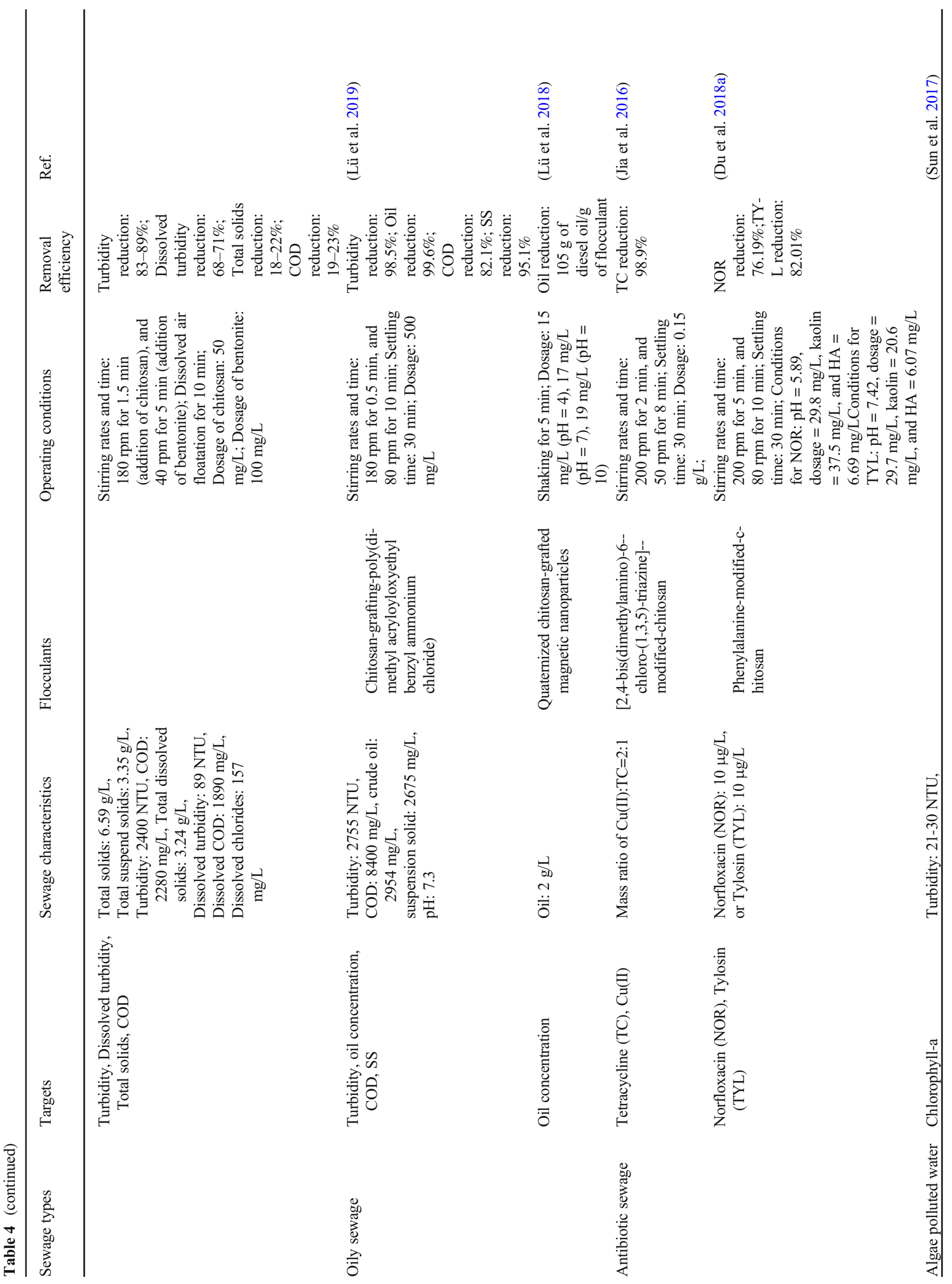




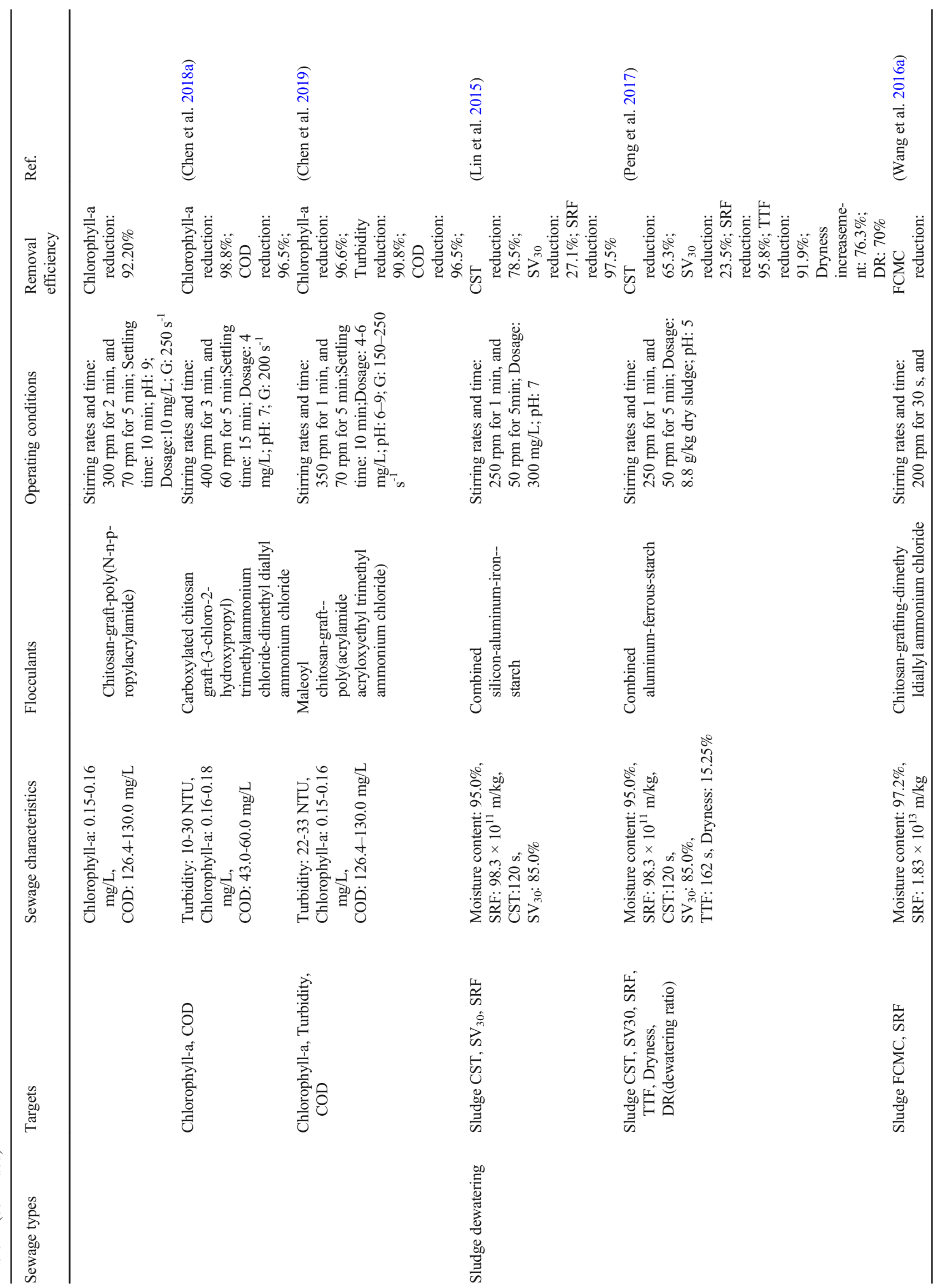


Besides, dye molecules absorb light in the water environment, inhibiting the photosynthesis of aquatic plants. Thus, the dissolved oxygen in water decreases, resulting in water quality deterioration (Jiang et al. 2017).

Dyes can be divided into cationic and anionic. For removing these two different forms of dye molecules, different functional groups of biopolymer-based flocculants are demanded. Hence, it is necessary to develop suitable biopolymer-based flocculants for removing cationic dyes and anionic dyes, respectively. For cationic dyes, sulfomethylated softwood kraft lignin could remove $99.1 \%$ of ethyl violet (cationic dye) from sewage, under the conditions of $\mathrm{pH}=9$ and initial dye concentration of $300 \mathrm{mg} / \mathrm{L}$ (He et al. 2016). For anionic dyes, the cationic lignin-based flocculant, prepared by the radical polymerization of (2-(methacryloyloxy) ethyl) trimethyl ammonium chloride and lignin, has good removal efficiency of two kinds of anionic dyes (reactive black 5, reactive orange 16). The optimal removal rates of reactive black 5 and reactive orange 16 could be higher than 98\% and 94\%, respectively (Wang et al. 2018).

In actual dye sewage, dyes may coexist with other contaminants. Thus, the effects of co-existing contaminants on dye removal by biopolymer-based flocculants were studied. However, for biopolymer-based flocculants, it was reported that dye removal efficiency of the suspended particle-dye binary polluted sewage might be better than that of the dye single polluted sewage (Zhao et al. 2018). The main reason is that, before biopolymer-based flocculants are added, some dye molecules in the binary polluted system have been adsorbed on the suspended particles. After that, it can be more easily removed by flocculation. For a reported graft dextran flocculant, the dye removal rates were $68.1 \%$ for congo red single polluted sewage, and $88.2 \%$ for kaolin-congo red binary system (Zhao et al. 2018). Besides, when biopolymer-based flocculants are used with inorganic coagulants to treat dyes, they can also enhance the resistance of coexisting contaminants (e.g., ions, kaolin particles, humic acid, etc.) (Guo et al. 2019), and improve the dye removal efficiency. A reported synergistic treatment using lignin-based flocculant and polyaluminum chloride was more effective in removing reactive blue than polyaluminum chloride alone. However, the dosing method of biopolymer-based flocculants in synergistic treatment with inorganic coagulants will impact the flocculation efficiency (Guo et al. 2018a). As mentioned above, biopolymer-based flocculants have strong anti-interference ability to eliminate the coexisting contaminants' interference, and can help the inorganic coagulants enhance the dyes removal efficiency.

The dyes removal efficiency of biopolymer-based flocculants is easily affected by molecular factors, such as the structure characteristics (branched vs. linear) and charge density. The dyes removal efficiency of branched molecules is better than that of linear molecules, because the flocs generated by branched flocculants have stronger resistance, as well as larger 
and looser structures. Thus, they are easier to settle down. However, if the amount of grafted branches is too large, it is easy to produce steric hindrance effect and hamper the removal of dyes (Guo et al. 2020). In terms of the charge density, a higher charge density of biopolymer-based flocculants could result in better dye removal efficiency (He et al. 2016).

\section{Heavy metal ions}

Heavy metal ions pollution is one of the main sources of natural water pollution. For one thing, it will harm aquatic organisms and human health; for another thing, the water polluted by heavy metal ions cannot be recycled, thus reducing the available water resources and causing economic losses (Sun et al. 2020b).

The composition of actual heavy metal sewage is often complex, which may contain some other kinds of contaminants or a variety of heavy metal ions. For example, electroplating wastewater contains not only heavy metal ions, but also COD, suspended particles, etc. For biopolymer-based flocculants, sometimes the sewage with multiple pollutants did not have a negative impact on the flocculation efficiency of heavy metal ions, but even promoted it. The main reason is that the chelate formed by biopolymer-based flocculants and heavy metal ions could react with COD and suspended particles through net trapping and adsorption bridging, thus improving the removal capacity of heavy metals (Sun et al. 2020b). A xanthated chitosan flocculant was reported for treating $\mathrm{Cu}(\mathrm{II})$ sewage. The maximum removal efficiency of $\mathrm{Cu}$ (II) was less than $92.4 \%$ in the treatment of $\mathrm{Cu}$ (II) single polluted sewage. However, the removal efficiency of $\mathrm{Cu}(\mathrm{II})$ could reach $93.6 \%$ in the treatment of turbidity-Cu(II) binary polluted sewage (Yang et al. 2018). The presence of turbidity could enhance the removal efficiency of biopolymer-based flocculants on heavy metal ions, but this enhancement only existed within a certain turbidity range (Sun et al. 2020b). However, if varied heavy metal ions coexisted in the sewage, there was a competitive relationship between the heavy metal ions to react with biopolymerbased flocculants (Sun et al. 2019b).

In addition, the $\mathrm{pH}$ value of sewage has a great influence on removing heavy metal ions by biopolymer-based flocculants. The lower the $\mathrm{pH}$ is, the less favorable it is for biopolymerbased flocculants to remove heavy metal ions (Sun et al. 2019b; Yang et al. 2018; Wu et al. 2018). In the low pH condition, some functional groups on biopolymer-based flocculants were protonated, and positive charges were accumulated on the molecular chain. It reduced the chelating ability of functional groups (Sun et al. 2019b), and decreased the collision of biopolymer-based flocculants with heavy metal ions (Yang et al. 2018).

Up to now, flocculation technology based on biopolymerbased flocculants has been able to enhance the treatment of heavy metal ions sewage. Firstly, with the aid of biopolymerbased flocculants, the flocculation performance of inorganic coagulants on heavy metal ions could be improved. Compared to using polyaluminium ferric chloride alone, combining it with a sulfonated chitosan-based flocculant to remove heavy metal ions could form bigger flocs, thus gain a better flocculation efficiency (Tang et al. 2020). Secondly, the removal efficiency of heavy metals by only using biopolymer-based flocculants has met the emission standards. For example, the reported two-stage flocculation technology based on biopolymer-based flocculants could remove $94.7 \%$ of $\mathrm{Cr}$ ions and $99.4 \%$ of Ni ions (Sun et al. 2019a). In their research, the concentration of residual heavy metal ions could meet the requirement of Chinese emission standards (GB21900-2008).

\section{Other industrial/agricultural processes}

\section{Pulp mill sewage}

The pulp mill sewage usually contains dissolved, insoluble, organic and inorganic substances. The insoluble substances are often in the form of fine particles, so it is tough to remove (Chen et al. 2018b).

Biopolymer-based flocculants with high charge density can remove contaminants from pulp mill sewage by charge neutralization and the bridging mechanism. A xylanpolymerizing (2-methacryloyloxyethyl) trimethyl ammonium chloride flocculant could reach the COD removal efficiency of $61.7 \%$ and the turbidity removal efficiency of $94.5 \%$ in pulp mill sewage treatment (Chen et al. 2018b). Nevertheless, it is worth noting that although higher charge density probably tends to enhance the flocculation of biopolymer-based flocculants on pulp mill sewage, the effect of molecular weight may be opposite (it was reported that the removal efficiency of biopolymer-based flocculants with low molecular weight was higher) (Miranda et al. 2013).

\section{Oily sewage}

Oily sewage comes from various industrial fields, such as petroleum, steel smelting, food, leather, etc. (Ma et al. 2018; Lü et al. 2019). The oily sewage is usually in the form of emulsion, hence increasing the difficulty to remove oil.

The surfaces of the oil droplets are negatively charged, thus can be removed by the biopolymer-based flocculants with cationic groups via electrostatic attraction. In addition, the introduction of hydrophobic groups can enhance the adsorption and bridging effect of biopolymer-based flocculants on oil droplets. For example, a chitosan-grafting-poly(dimethyl acryloyloxyethyl benzyl ammonium chloride) flocculant, which was prepared by introducing cationic and hydrophobic groups into chitosan by graft reaction, could remove more than $98 \%$ oil from oily sewage (Lü et al. 2019). Similarly, 
quaternized chitosan magnetic flocculants had positive surface charges, and could remove oil droplets through electrostatic interactions. The oil removal efficiency of them could reach $105 \mathrm{~g}$ of diesel oil/g of flocculants. The higher the cationic charge intensity was, the better the flocculation of oil droplets was (Lü et al. 2018).

\section{Antibiotic sewage}

The sources of antibiotic contaminants are usually livestock sewage and industrial sewage. Antibiotics and heavy metal ions often coexist in such sewage (Hou et al. 2019), which increases the difficulty of water treatment. Nonetheless, antibiotics entering the environment will cause antibiotics resistance of bacteria (Ben et al. 2008), which will threaten human health. It was reported that the death rate of drug-resistant strains would double (Sandberg et al. 2018). However, the emergence of biopolymer-based flocculants provides a new opportunity for removing antibiotics from sewage.

After modification, biopolymer-based flocculants may remove antibiotics by $\pi-\pi$ stacking, electrostatic attraction, hydrogen bond, hydrophobic association, etc. Aromatic rings, introduced into biopolymer-based flocculants, can interact with the aromatic rings on antibiotic molecules by $\pi-\pi$ stacking, thus improving the removal efficiency of antibiotics by biopolymer-based flocculants. For example, BDAT-CTS, a chitosan-based flocculant with triazine rings, can react with negative charged aromatic rings on tetracycline antibiotics. The removal efficiency of tetracycline and $\mathrm{Cu}$ (II) in mixed sewage by BDAT-CTS was $98.8 \%$ and $94.0 \%$, respectively (Jia et al. 2016). In another research, a phenylalanine-modified-chitosan flocculant with linear molecular architecture was reported. Owing to the introduction of aromatic rings, it could directly react with antibiotics by cation- $\pi$ interaction. At the same time, there were electrostatic attraction and hydrogen bond between the phenylalanine-modified-chitosan and antibiotics. The theoretical removal efficiencies of Norfloxacin and Tylosin in mixed sewage by phenylalanine-modified-chitosan flocculants were $76.19 \%$ and $82.01 \%$, respectively (Du et al. 2018a). Of course, biopolymer-based flocculants could also effectively remove antibiotics only through hydrogen bond and hydrophobic association. A thermoresponsive chitosan-based flocculant was used to treat tetracycline$\mathrm{Cu}$ (II) binary polluted sewage. Under optimal conditions, the removal efficiencies of tetracycline and $\mathrm{Cu}$ (II) could be both higher than $90 \%$ (Ren et al. 2017).

As antibiotics and heavy metal ions often coexist in sewage, the actual binding interactions between antibiotics and heavy metal ions would also have important impacts on the flocculation efficiency of antibiotics by biopolymer-based flocculants. Studies showed that the stronger the binding energies between antibiotics and heavy metal ions were, the easier it was for the antibiotics to be removed by biopolymer-based flocculants (Hou et al. 2019; Ren et al. 2017).

\section{Retention aids}

Retention aids are usually used in papermaking process. They play an important role in the aggregation of fillers and fine fiber powders in pulp suspension, and can improve the retention performance in the paper-making process (You et al. 2019). For the aim of non-toxicity, some studies try to use biopolymer-based flocculants as retention aids. For example, hairy cationic nanocrystalline cellulose was used as a retention aid in papermaking process. The results showed that adding $20 \mathrm{mg} / \mathrm{g}$ hairy cationic nanocrystalline cellulose could shorten the pulp drainage time by $78 \%$ and improve the retention by 77\% (Campano et al. 2019a). In another study, a kind of leather waste-based composite was prepared by using collagen wastes as starting materials. This flocculant has good retention performance, and the best retention rate was more than $85 \%$ at the dosage of 0.6 wt.\% (You et al. 2019). A starch-based flocculant was synthesized by graft copolymerization of starch with acrylamide (AM) and diallyldimethylammonium chloride (DADMAC). The results showed that the fillers retention of this flocculant was higher than that of cationic polyacrylamide when the dosage was $0.05 \%$, the intrinsic viscosity was 7.35 , and the cationic degree was $22 \%$ (Lu et al. 2004).

\section{Algae}

In the process of human production, a large number of nutrient elements, such as nitrogen and phosphorus, are discharged into the natural water body, which makes the water eutrophic, thus leading to the outbreak of algae (Sun et al. 2017). However, some algae can release toxins, which pose a serious threat to human and animal health (Liu et al. 2013). Besides, algae usually form a stable suspension in the water body and are difficult to remove owing to its negatively charged surface (Banerjee et al. 2012) and small size (Choy et al. 2018).

Compared with traditional flocculants, biopolymer-based flocculants have a better flocculation efficiency of algae. Sometimes, the same algae removal efficiency can be achieved even if the amount of biopolymer-based flocculants is less than that of inorganic coagulants. A cationized starchbased flocculant, which was obtained by modifying maize starch with glycidyltrimethylammonium chloride, was used for flocculating algae suspension. This cationized starchbased flocculant (substitution degree of 0.13 ), with only one-tenth the dosage of aluminum sulfate, could achieve a similar algae removal efficiency (El-Naggar et al. 2018). In another research, a carboxylated chitosan-based flocculant (CC-g-PCD) was used to treat the actual lake water containing 
algae. The dosage of it to achieve the optimal flocculation efficiency was only one-tenth of that of polyferric sulfate and polyaluminum chloride (Sun et al. 2019c). The algae flocculation efficiency of acrylamide- and dimethyl diallyl ammonium chloride-grafted chitosan [CS-g-P(AM-DMDAAC)] was better than that of traditional polyacrylamide and polymeric aluminum ferric flocculants. For CS-g-P(AMDMDAAC), the turbidity removal efficiency of low turbidity algae water could reach $99.02 \%$ (Sun et al. 2017). A carboxylated chitosan-based flocculant CPCTS-g-P (CTADMDAAC) had a better flocculation efficiency on microcystis aeruginosa polluted water than traditional flocculants (e.g., polyacrylamide, polyferric sulfate and polyaluminium chloride). Its removal efficiency of chlorophyll-a could reach $98.8 \%$ (Chen et al. 2018a). Similarly, a maleoyl chitosan-based flocculant [MHCS-g$\mathrm{P}(\mathrm{AM}-\mathrm{DAC})]$ had a better flocculation efficiency than the above mentioned three traditional flocculants in treating natural water containing algae. Its removal efficiency of chlorophyll-a could reach 96.6\% (Chen et al. 2019). Therefore, flocculation based on biopolymer-based flocculants is a promising water treatment method for algae removal.

\section{Sludge dewatering}

Sludge, which contains harmful contaminants adsorbed from the sewage, is produced in the process of sewage treatment. Therefore, sludge disposal is an important part of the sewage treatment process (Anjum et al. 2016; Wei et al. 2018a). The efficiency of sludge dewatering affects the subsequent transportation and operation costs (Mowla et al. 2013), so it is very important to improve the sludge dewatering efficiency. Flocculation is widely used for sludge dewatering (Wang et al. 2016a), which belongs to the category of chemical conditioning pretreatment of sludge (Wei et al. 2018a). Recently, the application of biopolymer-based flocculants in the flocculation for sludge dewatering is a hot research direction.

Compared with traditional inorganic coagulants and synthetic organic flocculants, biopolymer-based flocculants have a higher sludge dewatering efficiency and wider $\mathrm{pH}$ adaptability. For example, the combined silicon-aluminum-ferricstarch flocculant had a very good dewatering efficiency in the $\mathrm{pH}$ range of 3.0-11.0, and its dewatering efficiency was better than that of polyaluminum chloride, polyacrylamide, and ferric chloride (Lin et al. 2015). In another research, the combined aluminum-ferrous-starch flocculant (CAFS) was used in sludge dewatering. After the flocculation for sludge dewatering, CST, $\mathrm{SV}_{30}$, and SRF of sludge were $41.7 \mathrm{~s}, 65 \%$, and $4.1 \times 10^{11} \mathrm{~m} / \mathrm{kg}$, respectively. The sludge cake formed by the CAFS had lower compressibility than that of the traditional flocculants. Namely, the CAFS flocculant had a better dewatering efficiency (Peng et al. 2017). Under the same conditions of $\mathrm{pH}$ and dosage as the traditional flocculants, the
FCMC and SRF of sludge were $68.10 \%$ and $2.12 \times 10^{12}$ $\mathrm{m} / \mathrm{kg}$, respectively, after sludge dewatering with chitosangrafting-dimethy ldiallyl ammonium chloride (chitosan-gDMDAAC). The treatment efficiency was better than polyacrylamide and cationic polyacrylamide (Wang et al. 2016a). In another study, the chitosan-g-DMDAAC was used in the dewatering of anaerobically digested sludge. Within the optimal dosage, the CMC was $81.7 \%$, SRF was $2.64 \times 10^{8} \mathrm{~m} / \mathrm{kg}$, and CST was $1.31 \mathrm{~s} \cdot \mathrm{L}^{-\mathrm{g}^{-1}}$ (Zhang et al. 2019). In the $\mathrm{pH}$ range of 5-6, the carboxymethyl chitosan-graft-poly(acrylamidemethacryloxyethyltrimethyl ammonium chloride) flocculant could achieve the best efficiency on sludge dewatering. After flocculation for sludge dewatering, the moisture content was $76.26 \%$, and the SRF was $1.09 \times 10^{13} \mathrm{~m} / \mathrm{kg}$ (Shi et al. 2019). The experimental results of various studies showed that biopolymer-based flocculants could be used as an excellent substitute for traditional flocculants in sludge dewatering.

When biopolymer-based flocculants are used with inorganic coagulants for sludge dewatering, the dosing method will affect sludge dewatering efficiency. It was reported that the sludge dewatering efficiency of the starch-3-chloro-2-hydroxypropyl trimethylammonium chloride (St-WH) used with the inorganic coagulant $\mathrm{FeCl}_{3}$ was better than that of St-WH used alone. However, only by adding St-WH after $\mathrm{FeCl}_{3}$ during dosing was the sludge dewatering efficiency optimal. Through this dosing method, SRF and FCMC could reach $(0.25 \pm 0.01) \times 10^{12}$ $\mathrm{m} / \mathrm{kg},(81.2 \pm 0.6) \%$, respectively (Wei et al. 2018b).

\section{Pilot-scale test, full-scale test and practical application}

At present, most of the researches about biopolymer-based flocculants are laboratory-scale, and rare reports have pilotscale test, full-scale test, and practical application.

In terms of pilot-scale test and full-scale test, it is reported that raw water from the Zhenjiang section of the Yangtze River in China was used for pilot-scale test of chitosanbased flocculants. This process can reduce the turbidity of raw water from 33-50 NTU to 0.47 NTU; Even under shorter sedimentation time than the actual process, all the effluent parameters fully meet the Chinese drinking water quality standard GB 5749-2006 (Yang et al. 2011). Another study showed that the efficiency of a tannin-based flocculant was similar to or even better than that of batch trials (Sánchez-Martín et al. 2010). In the full-scale test, Moringa oleifera-derived coagulants were used to treat raw water with the turbidity of 270-380 NTU, and the effluent turbidity could be less than 4 NTU (Dorea 2006).

In terms of practical application, the materials based on Moringa oleifera have been widely used in developing countries (Beltrán-Heredia and Sánchez-Martín 2009; Baptista et al. 2015). In Egypt and Sudan, natural polypeptides produced from the seeds of Moringa oleifera have been used to produce drinking water. This simple water treatment 
technology has two methods. (i) Add Moringa oleifera seeds powder into raw water, stirring for about 5 minutes, standing for about 1 hour, and then purified water was obtained by filtration; (ii) Soak the cloth containing Moringa oleifera seeds powder in raw water overnight; Then, take out the cloth and use the supernatant. This simple technique can remove up to 99\% of the colloidal matters (Foidl et al. 2001).

However, there are still three limitations in this practical technology that has been used in developing countries. (i) The consumption of Moringa oleifera seeds is large. If Moringa oleifera seeds powder is used to treat domestic wastewater, it needs $96 \mathrm{~g}$ seeds/(person-day); (ii) The pre-concentrated form has a bitter taste. The pre-concentration is used to reduce the volume and weight of Moringa oleifera seeds, which would make the treated water taste bitter; (iii) Flocculation performance is not stable, and it will be affected by seasons (Foidl et al. 2001).

In general, the potential areas of application for biopolymer-based flocculants lie in three aspects. (i) biopolymer-based flocculants can be used with inorganic coagulants to reduce the dosage of inorganic coagulants (Li et al. 2018) and enhance the water treatment efficiency (Guo et al. 2018a; Tang et al. 2020). (ii) To resist the interference of coexisting pollutants (Nasim et al. 2018; Zhao et al. 2018) and extreme pH conditions (Ren et al. 2016), the use of biopolymer-based flocculants can greatly alleviate the impact of aqueous environment (Guo et al. 2019; Sun et al. 2020b). (iii) Biopolymer-based flocculants can completely replace inorganic coagulants to reduce the negative impact on the human body, such as Moringa oleifera used in developing countries (Beltrán-Heredia and Sánchez-Martín 2009; Baptista et al. 2015). As for the excellent flocculation performance of biopolymer-based flocculants pre-mentioned in (i) and (ii), many different kinds of biopolymers can achieve these properties after modification. In fact, the flocculation performance of biopolymer-based flocculants is largely affected by the types of grafted functional groups (e.g., cations (Wang et al. 2018), anions (He et al. 2016)), molecular weight, and charge density (Yang et al. 2016a) after modification, rather than affected by raw biopolymers themselves. However, from an economical point of view, as shown in Table 1, cellulose would be a preferred choice. Besides, in terms of practical application, Moringa oleifera flocculants have been widely used in developing countries (Beltrán-Heredia and SánchezMartín 2009; Baptista et al. 2015). Therefore, compared with other biopolymer-based flocculants, Moringa oleifera is an effective material with rich practical application experience.

\section{Perspectives}

In the future, the main changes of organic flocculants may appear in three aspects. (i) Properties optimization to adapt to extreme $\mathrm{pH}$ conditions and coexisting pollutants; (ii) Cost-benefit optimization; (iii) Reduction of residual polymers to avoid disinfection by-products. Moreover, to reduce the toxicity, the idea of combining synthetic organic flocculants with biopolymer-based flocculants can be further studied. At present, such kind of report is rare (Nasim et al. 2018). Among organic flocculants, polyacrylamide (PAM) is one of the most commonly used (Taylor et al. 2002). Beside its use as a flocculant, it is also widely used as cross-linking agent, thickener, liquid resistance reducer, and oil liquefying agent (Yen and Yang 2003), so that its market demand may continue to increase. However, the residual monomer of it, namely acrylamide, is highly neurotoxic and potentially carcinogenic (Lu et al. 2014), so that the market demand for safer biopolymer-based flocculants will not stop.

As a new type of water treatment agent, biopolymer-based flocculants have yet to be further developed. The main focus of biopolymer-based flocculants studies in the future should be as follows (Figure 6):

1. Sources upgrade: (i) Increase the sources and improve the extraction methods of biopolymers, in order to make them more economical and efficient. (ii) Discover more new biopolymers with excellent properties, for base materials of biopolymer-based flocculants.

2. Optimization of modification processes: (i) Discover new modifying reagents/monomers towards a greener and safer direction, because current widely used acrylamide monomers are highly neurotoxic and potentially carcinogenic (Lu et al. 2014). (ii) Optimize modification reactions to enhance the flocculation performance of biopolymer-based flocculants and their multifunctionality.

3. Combination of new functions: Biopolymers contain rich functional groups, which are conducive to modification. Therefore, the future multi-functional development of biopolymer-based flocculants is very promising. (i) Combination of new separation methods: To improve the contaminants flocculation efficiency and liquid-solid separation efficiency, a magnetic flocculation separation method has been developed (Lü et al. 2018; Liu et al. 2018a). In the future, more new separation methods of biopolymer-based flocculants may be developed, such as floatation separation, which was reported in the field of adsorbents (An et al. 2019b; An et al. 2020; An et al. 2019a). (ii) Combination of regenerative and reusable function (regenerated by temperature, $\mathrm{pH}$, and other conditions (Wang et al. 2016b)): At present, there are few biopolymer-based flocculants with the material regeneration and reuse function to make the flocculation of biopolymer-based flocculants more economical and environmentally friendly, which thus can be further developed. (iii) Combination of sterilization. Up to now, there have been 


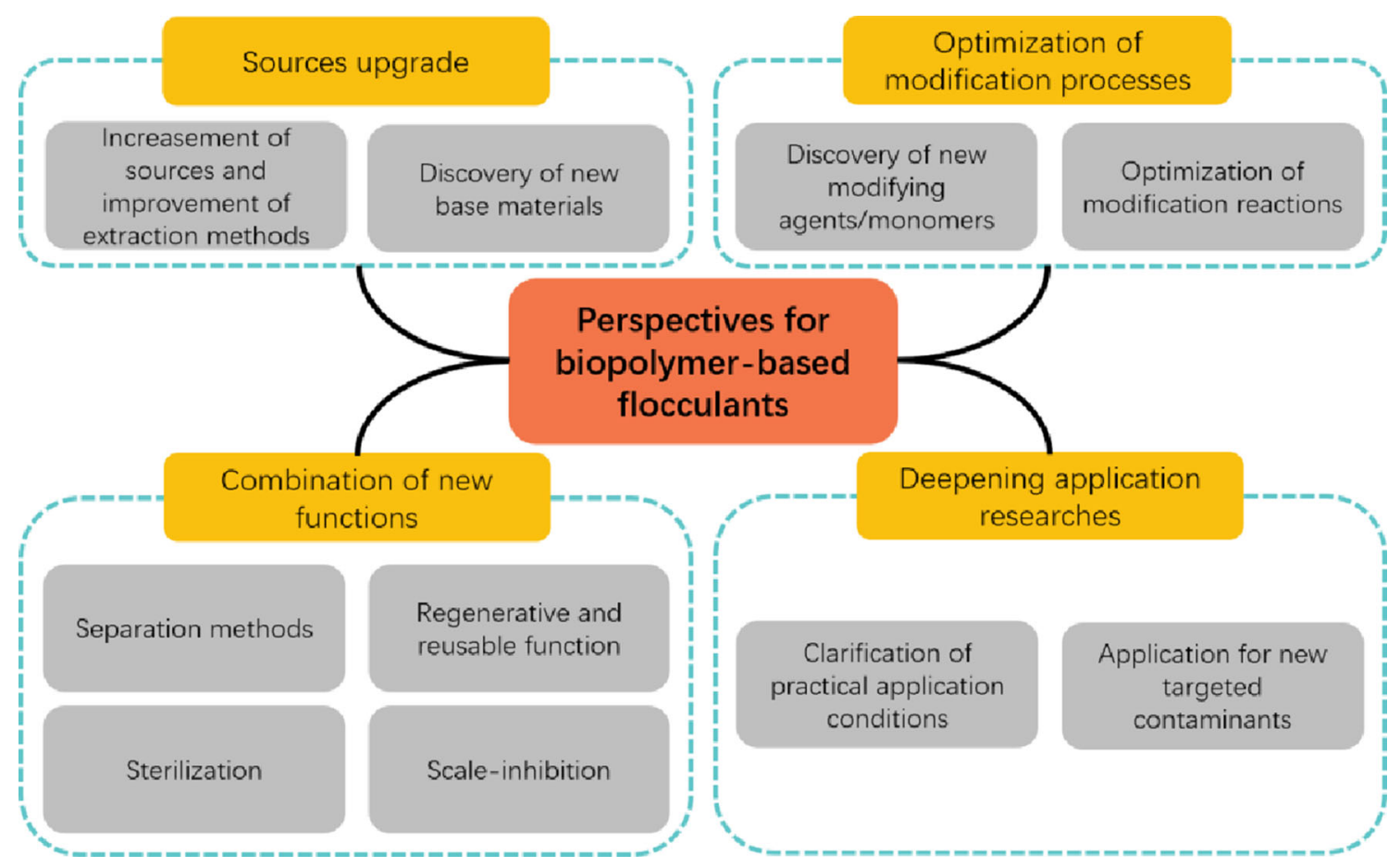

Fig. 6 Perspectives for biopolymer-based flocculants

some biopolymer-based flocculants combined with sterilization(Liu et al. 2017a; El-Naggar et al. 2018; Li et al. 2017; Chen et al. 2020b; Tang et al. 2010), but the sterilization efficiency of them still needs to be further improved. (iv) Combination of scale-inhibition (Du et al. 2018b): Preventing scale formation can improve water quality. However, the researches of biopolymer-based flocculants combined with scale-inhibition are still few.

4. Deepening application researches: (i) Clarification of practical application conditions: The practical application of many newly developed biopolymer-based flocculants is still less studied. In practical application, biopolymer-based flocculants are restricted by many uncertain factors such as unknown production cost and nonstandard production process. Therefore, it is necessary to carry out cost-benefit analysis and process standardization of biopolymer-based flocculants for practical application; (ii) Application for new targeted contaminants: Newly emerging targeted pollutants refer to the pollutants produced by newly discovered sources(EPA U 2012). Their emergence in the environment poses a major risk to the ecosystem. These newly emerging targeted pollutants are mainly divided into two categories: synthetic compounds (e.g., microplastics, detergents, pesticides, personal care products, pharmaceuticals, disinfection by-products, flame-retardants) (Teodosiu et al. 2018) and natural chemicals (e.g., hormones) (Dimpe and Nomngongo 2016). With the increasingly complex water pollution situation, the newly emerging pollutants will inevitably appear, so biopolymer-based flocculants face new challenges. For example, recent researches on flocculation removal of microplastics have started (Rajala et al. 2020), but the application of biopolymer-based flocculants in this field is rare. A microalgal-based biopolymer was used to treat water polluted by nano- and microplastics. The results showed that the microalgal-based biopolymer could provide a biocompatible solution for the microplastics' polluted water (Cunha et al. 2020). Another study suggested that biopolymers could destroy the stability of latex microplastics particles more effectively than aluminum chloride in some cases, and form flocs with a more compact structure thus increasing the sedimentation rate (Ramirez et al. 2016).

In the future, biopolymer-based flocculants may be more and more used to assist and even replace traditional flocculants. In addition, due to the material safety of biopolymerbased flocculants, the market demand for emergency water usage and point-of-use water treatment (Saifuddin et al. 2011; Dhiman and Agnihotri 2020) may increase.

\section{Conclusion}

This paper reviews the recent important information about biopolymer-based flocculants, including the current commonly used base materials, the latest modification methods, the flocculation mechanisms, and the recent applications. The base materials of biopolymer-based flocculants include chitosan, starch, cellulose, lignin, etc. These materials are rich in natural reserves and can be extracted from a wide range of sources, such as animals, plants, fungi, etc. Therefore, they are very 
reproducible. In order to enhance the flocculation or the multifunctionality of biopolymer-based flocculants, many researches developed different modification methods for biopolymers. The latest modification methods include graft copolymerization (thermal initiation, photo initiation, radiation initiation, microwave initiation, plasma initiation), etherification, amination, esterification, acylation, oxidation, cross-linking, and Mannich reaction. Most of these modification methods are based on hydroxyl and amino groups of biopolymers. Through these different modification methods mentioned above, biopolymer-based flocculants may get various structural characteristics (functional groups, molecular weight, charge density, etc.), so that biopolymer-based flocculants can treat sewage through a variety of flocculation mechanisms. The main flocculation mechanisms of biopolymerbased flocculants include adsorption, bridging, charge neutralization, net trapping, and sweeping, as well as hydrophobic interaction effect, coordination effect, chelation, $\pi-\pi$ stacking.

Compared with those of traditional flocculants, the applications of biopolymer-based flocculants have become more diversified, due to their rich flocculation mechanisms. Biopolymer-based flocculants can be used to treat turbidity, dyes, heavy metal ions, and other industrial/agricultural processes (pulp mill wastewater, oily wastewater, antibiotic wastewater, and retention aids), as well as algae capture and sludge dewatering. The potential areas of application for biopolymer-based flocculants lie in three aspects. (i) Biopolymer-based flocculants can be used with inorganic coagulants to reduce the dosage of inorganic coagulants and enhance the water treatment efficiency. (ii) To resist the interference of coexisting pollutants and extreme $\mathrm{pH}$ conditions, the use of biopolymer-based flocculants can greatly alleviate the impact of aqueous environment. (iii) Biopolymer-based flocculants can completely replace inorganic coagulants to reduce the negative impact on the human body, such as Moringa oleifera used in developing countries. As for the excellent flocculation performance of biopolymerbased flocculants pre-mentioned in (i) and (ii), many different kinds of biopolymers can achieve these properties after modification. In fact, the flocculation performance of biopolymer-based flocculants is largely affected by the types of grafted functional groups (e.g., cations, anions), molecular weight, and charge density after modification, rather than affected by raw biopolymers themselves; However, from an economical point of view, cellulose would be a preferred choice; Besides, in terms of practical application, Moringa oleifera flocculants are effective materials with rich practical application experience.

In the future, researches on biopolymer-based flocculants may make progress in four directions. (i) Sources upgrade: increase of biopolymers sources, improvement of extraction methods, and discovery of new base materials; (ii) Optimization of modification processes: discovery of new modifying agents/monomers, and optimization of modification reactions; (iii) Combination of new functions: separation methods, regenerative and reusable function, sterilization and scale-inhibition; (iv) Deepening application researches: clarification of practical application conditions (cost-benefit analysis and process standardization), and application for new targeted contaminants. We expect that this review will encourage and guide the further researches and developments of biopolymer-based flocculants in the future. Development of affordable, safe, multifunctional biopolymer-based flocculants with enhanced efficiency should offer sustainable solutions by replacing the synthetic counterparts.

Author contribution Xincheng Jiang: Conceptualization, Methodology, Software, Visualization, Writing-original draft, Writing-review \& editing, Validation. Yisen Li: Conceptualization, Methodology, Software, Visualization, Investigation, Validation, Writing-review \& editing. Xiaohui Tang: Conceptualization, Methodology, Software, Visualization, Investigation, Validation. Junyi Jiang: Conceptualization, Methodology, Software, Writing-original draft. Qiang He: Conceptualization, Methodology, Software, Visualization, Investigation, Validation Writing-review \& editing. Zikang Xiong: Conceptualization, Methodology, Software, Visualization, Investigation. Huaili Zheng: Conceptualization, Methodology, Software, Visualization, Writing-original draft, Writing-review \& editing, Validation.

Funding This research was supported by the National Natural Science Foundation of China (Project No. 21677020) and State Education Ministry and the Fundamental Research Funds for the Central Universities (Project No. 2019 CDJSK 04 XK23).

Data availability The manuscript has no associated data.

\section{Declarations}

Ethics approval We agree and approve the ethical responsibilities of authors.

Consent to participate All authors whose names appear on the submission (1) made substantial contributions to the conception or design of the

work; (2) drafted the work or revised it critically; (3) approved the version to be published; and (4) agreed to be accountable for all aspects of the work in ensuring that questions related to the accuracy or integrity of any part of the work are appropriately investigated and resolved.

Consent for publication All authors agreed with the content and that all gave explicit consent to submit and publish. They obtained consent from the responsible authorities at the institute/organization where the work has been carried out.

Competing interests The authors declare no competing interests. 


\section{References}

Abels C, Thimm K, Wulfhorst H, Spiess AC, Wessling M (2013) Membrane-based recovery of glucose from enzymatic hydrolysis of ionic liquid pretreated cellulose. Bioresource Technology 149: 58-64. https://doi.org/10.1016/j.biortech.2013.09.012

Achinivu EC (2018) Protic ionic liquids for lignin extraction - a lignin characterization study. International Journal of Molecular Sciences 19(2):428

Agbovi HK, Wilson LD (2018) Design of amphoteric chitosan flocculants for phosphate and turbidity removal in wastewater. Carbohydrate Polymers 189:360-370. https://doi.org/10.1016/j. carbpol.2018.02.024

Altemimi AB (2018) Extraction and optimization of potato starch and its application as a stabilizer in yogurt manufacturing. Foods 7(2):14

An Y, Zheng H, Sun Q, Zheng X, Wu Q, Zhao R (2019a) A novel floating adsorbents system of acid orange 7 removal: polymer grafting effect. Separation and Purification Technology 227: 115677. https://doi.org/10.1016/j.seppur.2019.115677

An Y, Zheng H, Zheng X, Sun Q, Zhou Y (2019b) Use of a floating adsorbent to remove dyes from water: a novel efficient surface separation method. Journal of Hazardous Materials 375:138-148. https://doi.org/10.1016/j.jhazmat.2019.04.060

An Y, Zheng H, Yu Z, Sun Y, Wang Y, Zhao C, Ding W (2020) Functioned hollow glass microsphere as a self-floating adsorbent: rapid and high-efficient removal of anionic dye. Journal of Hazardous Materials 381:120971. https://doi.org/10.1016/j. jhazmat.2019.120971

Anjum M, Al-Makishah NH, Barakat MA (2016) Wastewater sludge stabilization using pre-treatment methods. Process Safety and Environmental Protection 102:615-632. https://doi.org/10.1016/j. psep.2016.05.022

Arni SA (2018) Extraction and isolation methods for lignin separation from sugarcane bagasse: a review. Industrial Crops and Products 115:330-339. https://doi.org/10.1016/j.indcrop.2018.02.012

Banerjee C, Gupta P, Mishra S, Sen G, Shukla P, Bandopadhyay R (2012) Study of polyacrylamide grafted starch based algal flocculation towards applications in algal biomass harvesting. International Journal of Biological Macromolecules 51(4):456-461. https://doi. org/10.1016/j.ijbiomac.2012.06.011

Baptista ATA, Coldebella PF, Cardines PHF, Gomes RG, Vieira MF, Bergamasco R, Vieira AMS (2015) Coagulation-flocculation process with ultrafiltered saline extract of Moringa oleifera for the treatment of surface water. Chemical Engineering Journal 276:166-173. https://doi.org/10.1016/j.cej.2015.04.045

Beltrán-Heredia J, Sánchez-Martín J (2009) Removal of sodium lauryl sulphate by coagulation/flocculation with Moringa oleifera seed extract. Journal of Hazardous Materials 164(2):713-719. https://doi. org/10.1016/j.jhazmat.2008.08.053

Ben W, Qiang Z, Adams C, Zhang H, Chen L (2008) Simultaneous determination of sulfonamides, tetracyclines and tiamulin in swine wastewater by solid-phase extraction and liquid chromatographymass spectrometry. Journal of Chromatography A 1202(2):173180. https://doi.org/10.1016/j.chroma.2008.07.014

Bernardo CO, Ascheri JLR, Chávez DWH, Carvalho CWP (2018) Ultrasound assisted extraction of yam (Dioscorea bulbífera) starch: effect on morphology and functional properties. Starch - Stärke 70(5-6):1700185. https://doi.org/10.1002/star.201700185

Bhalkaran S, Wilson LD (2016) Investigation of self-assembly processes for chitosan-based coagulant-flocculant systems: a mini-review. International journal of molecular sciences 17(10): 1662

Bolto B, Gregory J (2007a) Organic polyelectrolytes in water treatment. Water Research 41(11):2301-2324. https://doi.org/10.1016/j. watres.2007.03.012
Bolto BA, Gregory J (2007b) Organic polyelectrolytes in water treatment. Water Research 41(11):2301-2324

Brenelli LB, Mandelli F, Mercadante AZ, Rocha GJM, Rocco SA, Craievich AF, Goncalves AR, Centeno DDC, Neto MDO, Squina FM (2016) Acidification treatment of lignin from sugarcane bagasse results in fractions of reduced polydispersity and high free-radical scavenging capacity. Industrial Crops and Products 83:94-103

Cai T, Li H, Yang R, Wang Y, Li R, Yang H, Li A, Cheng R (2015) Efficient flocculation of an anionic dye from aqueous solutions using a cellulose-based flocculant. Cellulose 22(2):1439-1449

Campano C, Lopez-Exposito P, Blanco A, Negro C, van de Ven TG (2019a) Hairy cationic nanocrystalline cellulose as retention additive in recycled paper. Cellulose 26(10):6275-6289

Campano C, Lopez-Exposito P, Blanco A, Negro C, van de Ven TGM (2019b) Hairy cationic nanocrystalline cellulose as a novel flocculant of clay. Journal of Colloid and Interface Science 545:153-161. https://doi.org/10.1016/j.jcis.2019.02.097

Can İB, Bıçak Ö, Özçelik S, Can M, Ekmekçi Z (2020) Sulphate removal from flotation process water using ion-exchange resin column system. Minerals 10(8):655

Chen L, Liu C, Sun Y, Sun W, Xu Y, Zheng H (2018a) Synthesis and characterization of ampholytic flocculant CPCTS-g-P (CTADMDAAC) and its flocculation properties for microcystis aeruginosa removal. Processes 6(5):54

Chen X, Si C, Fatehi P (2018b) Cationic xylan- (2-methacryloyloxyethyl trimethyl ammonium chloride) polymer as a flocculant for pulping wastewater. Carbohydrate Polymers 186:358-366. https://doi.org/ 10.1016/j.carbpol.2018.01.068

Chen L, Sun Y, Sun W, Shah KJ, Xu Y, Zheng H (2019) Efficient cationic flocculant MHCS-g-P(AM-DAC) synthesized by UVinduced polymerization for algae removal. Separation and Purification Technology 210:10-19. https://doi.org/10.1016/j. seppur.2018.07.090

Chen N, Liu W, Huang J, Qiu X (2020a) Preparation of octopus-like lignin-grafted cationic polyacrylamide flocculant and its application for water flocculation. International Journal of Biological Macromolecules 146:9-17

Chen W, Rong X, Peng J, Tang Q, Luo H, Fan L, Feng K, Zheng H (2020b) Assessment of a novel nanostructured flocculant with elevated flocculation and antimicrobial activity. Chemosphere 239: 124736. https://doi.org/10.1016/j.chemosphere.2019.124736

Chio C, Sain M, Qin W (2019) Lignin utilization: a review of lignin depolymerization from various aspects. Renewable and Sustainable Energy Reviews 107:232-249. https://doi.org/10. 1016/j.rser.2019.03.008

Choy SY, Prasad KMN, Wu TY, Raghunandan ME, Phang S-M, Juan JC, Ramanan RN (2018) Starch-based flocculant outperformed aluminium sulfate hydrate and polyaluminium chloride through effective bridging for harvesting acicular microalga Ankistrodesmus. Algal Research 29:343-353. https://doi.org/10.1016/j.algal.2017. 11.001

Cunha C, Silva L, Paulo J, Faria M, Nogueira N, Cordeiro N (2020) Microalgal-based biopolymer for nano- and microplastic removal: a possible biosolution for wastewater treatment. Environmental Pollution 263:114385. https://doi.org/10.1016/j.envpol.2020. 114385

Dao VH, Cameron NR, Saito K (2016) Synthesis, properties and performance of organic polymers employed in flocculation applications. Polymer Chemistry 7(1):11-25

Dhiman NK, Agnihotri S (2020) Hierarchically aligned nano silver/chitosan-PVA hydrogel for point-of-use water disinfection: contactactive mechanism revealed. Environmental Science: Nano 7(8): 2337-2350

Dimpe KM, Nomngongo PN (2016) Current sample preparation methodologies for analysis of emerging pollutants in different 
environmental matrices. TrAC Trends in Analytical Chemistry 82: 199-207. https://doi.org/10.1016/j.trac.2016.05.023

Dorea CC (2006) Use of Moringa spp. seeds for coagulation: a review of a sustainable option. Water Supply 6(1):219-227. https://doi.org/10. 2166/ws.2006.027

Du H, Yang Z, Tian Z, Huang M, Yang W, Zhang L, Li A (2018a) Enhanced removal of trace antibiotics from turbid water in the coexistence of natural organic matters using phenylalanine-modifiedchitosan flocculants: effect of flocculants' molecular architectures. Chemical Engineering Journal 333:310-319. https://doi.org/10. 1016/j.cej.2017.09.171

Du Q, Wang Y, Li A, Yang H (2018b) Scale-inhibition and flocculation dual-functionality of poly(acrylic acid) grafted starch. Journal of Environmental Management 210:273-279. https://doi.org/10.1016/ j.jenvman.2018.01.016

Duan C, Meng X, Meng J, Khan MIH, Dai L, Khan A, An X, Zhang J, Huq T, Ni Y (2019) Chitosan as a preservative for fruits and vegetables: a review on chemistry and antimicrobial properties. Journal of Bioresources and Bioproducts 4(1):11-21. https://doi.org/10. 21967/jbb.v4i1.189

Dulong V, Lack S, Le Cerf D, Picton L, Vannier JP, Muller G (2004) Hyaluronan-based hydrogels particles prepared by crosslinking with trisodium trimetaphosphate. Synthesis and characterization. Carbohydrate Polymers 57(1):1-6. https://doi.org/10.1016/j. carbpol.2003.12.006

El Halal SLM, Kringel DH, Zavareze ER, Dias ARG (2019) Methods for extracting cereal starches from different sources: a review. Starch Stärke 71(11-12):1900128. https://doi.org/10.1002/star.201900128

El Knidri H, Belaabed R, Addaou A, Laajeb A, Lahsini A (2018) Extraction, chemical modification and characterization of chitin and chitosan. International Journal of Biological Macromolecules 120:1181-1189. https://doi.org/10.1016/j.ijbiomac.2018.08.139

El-Naggar ME, Samhan FA, Salama AAA, Hamdy RM, Ali GH (2018) Cationic starch: Safe and economic harvesting flocculant for microalgal biomass and inhibiting E. coli growth. International Journal of Biological Macromolecules 116:1296-1303. https://doi. org/10.1016/j.ijbiomac.2018.05.105

EPA U (2012) Emerging contaminants-perfluorooctane sulfonate (PFOS) and perflu-orooctanoic acid (PFOA). Emerging contaminants fact sheet-PFOS and PFOA

Fanta GF, Burr RC, Doane WM, Russell CR (1972) Graft copolymers of starch with mixtures of acrylamide and the nitric acid salt of dimethylaminoethyl methacrylate. Journal of Applied Polymer Science 16(11):2835-2845

Feng Y-H, Cheng T-Y, Yang W-G, Ma P-T, He H-Z, Yin X-C, Yu X-X (2018) Characteristics and environmentally friendly extraction of cellulose nanofibrils from sugarcane bagasse. Industrial Crops and Products 111:285-291. https://doi.org/10.1016/j.indcrop.2017.10. 041

Ferraz CA, Fontes RLS, Fontes-Sant'Ana GC, Calado V, López EO, Rocha-Leão MHM (2019) Extraction, modification, and chemical, thermal and morphological characterization of starch from the agroindustrial residue of mango (Mangifera indica L) var. Ubá. Starch Stärke 71(1-2):1800023. https://doi.org/10.1002/star.201800023

Filho CMC, Bueno PVA, Matsushita AFY, Rubira AF, Muniz EC, Duraes L, Murtinho D, Valente AJM (2018) Synthesis, characterization and sorption studies of aromatic compounds by hydrogels of chitosan blended with $\beta$-cyclodextrin- and PVA-functionalized pectin. RSC Advances 8(26):14609-14622

Foidl N, Makkar H, Becker K (2001) The potential of Moringa oleifera for agricultural and industrial uses. What development potential for Moringa products 20

Fu W, Zhang W (2018) Microwave-enhanced membrane filtration for water treatment. Journal of Membrane Science 568:97-104. https://doi.org/10.1016/j.memsci.2018.09.064
Fujita S, Sakairi N (2016) Water soluble EDTA-linked chitosan as a zwitterionic flocculant for $\mathrm{pH}$ sensitive removal of $\mathrm{Cu}$ (ii) ion. RSC Advances 6(13):10385-10392. https://doi.org/10.1039/ C5RA24175H

Ghashoghchi RA, Hosseini MR, Ahmadi A (2017) Effects of microbial cells and their associated extracellular polymeric substances on the bio-flocculation of kaolin and quartz. Applied Clay Science 138:8188. https://doi.org/10.1016/j.clay.2017.01.002

Goodman BA (2020) Utilization of waste straw and husks from rice production: a review. Journal of Bioresources and Bioproducts 5(3):143-162. https://doi.org/10.1016/j.jobab.2020.07.001

Guo K, Gao B, Li R, Wang W, Yue Q, Wang Y (2018a) Flocculation performance of lignin-based flocculant during reactive blue dye removal: comparison with commercial flocculants. Environmental Science and Pollution Research 25(3):2083-2095. https://doi.org/ 10.1007/s11356-017-0835-Z

Guo K, Gao B, Yue Q, Xu X, Li R, Shen X (2018b) Characterization and performance of a novel lignin-based flocculant for the treatment of dye wastewater. International Biodeterioration \& Biodegradation 133:99-107

Guo K, Gao B, Wang W, Yue Q, Xu X (2019) Evaluation of molecular weight, chain architectures and charge densities of various ligninbased flocculants for dye wastewater treatment. Chemosphere 215: 214-226. https://doi.org/10.1016/j.chemosphere.2018.10.048

Guo K, Gao Y, Gao B, Feng Q, Shen X, Liu C, Yue Q, Xu X (2020) Structure-activity relationships of the papermill sludge-based flocculants in different dye wastewater treatment. Journal of Cleaner Production 266:121944. https://doi.org/10.1016/j.jclepro.2020. 121944

Harini K, Ramya K, Sukumar M (2018) Extraction of nano cellulose fibers from the banana peel and bract for production of acetyl and lauroyl cellulose. Carbohydrate Polymers 201:329-339. https://doi. org/10.1016/j.carbpol.2018.08.081

He W, Zhang Y, Fatehi P (2016) Sulfomethylated kraft lignin as a flocculant for cationic dye. Colloids and Surfaces A: Physicochemical and Engineering Aspects 503:19-27. https://doi.org/10.1016/j. colsurfa.2016.05.009

Hodásová L, Jablonsky M, Butor Skulcova A, Haz A (2015) Lignin, potential products and their market value. Wood Research 60:973986

Hokkanen S, Repo E, Sillanpää M (2013) Removal of heavy metals from aqueous solutions by succinic anhydride modified mercerized nanocellulose. Chemical Engineering Journal 223:40-47. https:// doi.org/10.1016/j.cej.2013.02.054

Hou T, Du H, Yang Z, Tian Z, Shen S, Shi Y, Yang W, Zhang L (2019) Flocculation of different types of combined contaminants of antibiotics and heavy metals by thermo-responsive flocculants with various architectures. Separation and Purification Technology 223:123132. https://doi.org/10.1016/j.seppur.2019.04.068

Huang M, Wang Y, Cai J, Bai J, Yang H, Li A (2016) Preparation of dual-function starch-based flocculants for the simultaneous removal of turbidity and inhibition of Escherichia coli in water. Water Research 98:128-137. https://doi.org/10.1016/j.watres.2016.04.009

Jia S, Yang Z, Yang W, Zhang T, Zhang S, Yang X, Dong Y, Wu J, Wang Y (2016) Removal of $\mathrm{Cu}(\mathrm{II})$ and tetracycline using an aromatic rings-functionalized chitosan-based flocculant: enhanced interaction between the flocculant and the antibiotic. Chemical Engineering Journal 283:495-503. https://doi.org/10.1016/j.cej. 2015.08 .003

Jiang J (2015) The role of coagulation in water treatment. Current Opinion in Chemical Engineering 8:36-44

Jiang Z, Hu C (2016) Selective extraction and conversion of lignin in actual biomass to monophenols: a review. Journal of Energy Chemistry 25(6):947-956. https://doi.org/10.1016/j.jechem.2016. 10.008 
Jiang F, Dinh DM, Hsieh Y-L (2017) Adsorption and desorption of cationic malachite green dye on cellulose nanofibril aerogels. Carbohydrate Polymers 173:286-294. https://doi.org/10.1016/j. carbpol.2017.05.097

Khiari R, Dridi-Dhaouadi S, Aguir C, Mhenni MF (2010) Experimental evaluation of eco-friendly flocculants prepared from date palm rachis. Journal of Environmental Sciences 22(10):1539-1543. https:// doi.org/10.1016/S1001-0742(09)60286-2

Kouadri I, Satha H (2018) Extraction and characterization of cellulose and cellulose nanofibers from Citrullus colocynthis seeds. Industrial Crops and Products 124:787-796. https://doi.org/10.1016/j.indcrop. 2018.08.051

Lama S, Muylaert K, Karki TB, Foubert I, Henderson RK, Vandamme D (2016) Flocculation properties of several microalgae and a cyanobacterium species during ferric chloride, chitosan and alkaline flocculation. Bioresource Technology 220:464-470. https://doi.org/10. 1016/j.biortech.2016.08.080

Le OTH, Tran LN, Doan VT, Pham QV, Ngo AV, Nguyen HH (2020) Mucilage extracted from dragon fruit peel (Hylocereus undatus) as flocculant for treatment of dye wastewater by coagulation and flocculation process. International Journal of Polymer Science 2020: 7468343-7468349. https://doi.org/10.1155/2020/7468343

Lee CS, Robinson J, Chong MF (2014) A review on application of flocculants in wastewater treatment. Process Safety and Environmental Protection 92(6):489-508. https://doi.org/10.1016/j.psep.2014.04. 010

Lee Y, Kim H-W, Brad Kim YH (2018) New route of chitosan extraction from blue crabs and shrimp shells as flocculants on soybean solutes. Food Science and Biotechnology 27(2):461-466. https://doi.org/10. 1007/s10068-017-0270-4

Lewicka K, Siemion P, Kurcok P (2015) Chemical modifications of starch: microwave effect. International Journal of Polymer Science 2015(2015):1-10

Li S, Zhou P, Yao P, Wei Y, Zhang Y, Yue W (2010) Preparation of Ocarboxymethyl-N-trimethyl chitosan chloride and flocculation of the wastewater in sugar refinery. Journal of Applied Polymer Science 116(5):2742-2748

Li O, Lu C, Liu A, Zhu L, Wang P-M, Qian C-D, Jiang X-H, Wu X-C (2013) Optimization and characterization of polysaccharide-based bioflocculant produced by Paenibacillus elgii B69 and its application in wastewater treatment. Bioresource Technology 134:87-93. https://doi.org/10.1016/j.biortech.2013.02.013

Li X, Zheng H, Wang Y, Sun Y, Xu B, Zhao C (2017) Fabricating an enhanced sterilization chitosan-based flocculants: synthesis, characterization, evaluation of sterilization and flocculation. Chemical Engineering Journal 319:119-130. https://doi.org/10.1016/j.cej. 2017.02.147

Li M, Wang Y, Hou X, Wan X, Xiao H-N (2018) DMC-grafted cellulose as green-based flocculants for agglomerating fine kaolin particles. Green Energy \& Environment 3(2):138-146. https://doi.org/10. 1016/j.gee.2017.11.005

Liao Y, Zheng H, Dai L, Li F, Zhu G, Qingqing G, Sun Y, Tang X (2014) Hydrophobically modified polyacrylamide synthesis and application in water treatment. Asian Journal of Chemistry 26:59235927. https://doi.org/10.14233/ajchem.2014.16860

Lin Q, Peng H, Zhong S, Xiang J (2015) Synthesis, characterization, and secondary sludge dewatering performance of a novel combined silicon-aluminum-iron-starch flocculant. Journal of Hazardous Materials 285:199-206. https://doi.org/10.1016/j.jhazmat.2014.12. 005

Lin Z, Wang Y, Huang W, Wang J, Chen L, Zhou J, He Q (2019) Singlestage denitrifying phosphorus removal biofilter utilizing intracellular carbon source for advanced nutrient removal and phosphorus recovery. Bioresource Technology 277:27-36. https://doi.org/10. 1016/j.biortech.2019.01.025
Liu D, Wang P, Wei G, Dong W, Hui F (2013) Removal of algal blooms from freshwater by the coagulation-magnetic separation method. Environmental Science and Pollution Research 20(1):60-65. https://doi.org/10.1007/s11356-012-1052-4

Liu Z, Huang M, Li A, Yang H (2017a) Flocculation and antimicrobial properties of a cationized starch. Water Research 119:57-66. https:// doi.org/10.1016/j.watres.2017.04.043

Liu Z, Wei H, Li A, Yang H (2017b) Evaluation of structural effects on the flocculation performance of a co-graft starch-based flocculant. Water Research 118:160-166. https://doi.org/10.1016/j.watres. 2017.04.032

Liu B, Chen X, Zheng H, Wang Y, Sun Y, Zhao C, Zhang S (2018a) Rapid and efficient removal of heavy metal and cationic dye by carboxylate-rich magnetic chitosan flocculants: role of ionic groups. Carbohydrate Polymers 181:327-336

Liu B, Zheng H, Wang Y, Chen X, Zhao C, An Y, Tang X (2018b) A novel carboxyl-rich chitosan-based polymer and its application for clay flocculation and cationic dye removal. Sci Total Environ 640 641:107-115

Liu Z, Xu D, Xia N, Zhao X, Kong F, Wang S, Fatehi P (2018c) Preparation and application of phosphorylated xylan as a flocculant for cationic ethyl violet dye. Polymers 10(3):317

Liu Y, Zheng H, An Y, Ren J, Zheng X, Zhao C, Zhang S (2019) Ultrasound-assisted synthesis of the $\beta$-cyclodextrin based cationic polymeric flocculants and evaluation of flocculation performance: Role of $\beta$-cyclodextrin. Separation and Purification Technology 228:115735. https://doi.org/10.1016/j.seppur.2019.115735

Liu Y, Zheng H, Sun Y, Ren J, Zheng X, Sun Q, Jiang S, Ding W (2020) Synthesis of novel chitosan-based flocculants with amphiphilic structure and its application in sludge dewatering: role of hydrophobic groups. Journal of Cleaner Production 249:119350

Lu S, Lin S, Yao K (2004) Study on the synthesis and application of Starch-graft-Poly(AM-co-DADMAC) by using a complex initiation system of CS-KPS. Starch - Stärke 56(3-4):138-143. https://doi.org/ 10.1002/star.200300229

Lu L, Pan Z, Hao N, Peng W (2014) A novel acrylamide-free flocculant and its application for sludge dewatering. Water Research 57:304 312. https://doi.org/10.1016/j.watres.2014.03.047

Lü T, Zhang S, Qi D, Zhang D, Zhao H (2018) Enhanced demulsification from aqueous media by using magnetic chitosan-based flocculant. Journal of Colloid and Interface Science 518:76-83. https://doi.org/ 10.1016/j.jcis.2018.02.024

Lü T, Luo C, Qi D, Zhang D, Zhao H (2019) Efficient treatment of emulsified oily wastewater by using amphipathic chitosan-based flocculant. Reactive and Functional Polymers 139:133-141. https://doi.org/10.1016/j.reactfunctpolym.2019.03.019

Ma J, Shi J, Ding L, Zhang H, Zhou S, Wang Q, Fu X, Jiang L, Fu K (2018) Removal of emulsified oil from water using hydrophobic modified cationic polyacrylamide flocculants synthesized from low-pressure UV initiation. Separation and Purification Technology 197:407-417. https://doi.org/10.1016/j.seppur.2018. 01.036

Mannich C, Krösche W (1912) Ueber ein Kondensationsprodukt aus Formaldehyd, Ammoniak und Antipyrin. Archiv der Pharmazie 250(1):647-667. https://doi.org/10.1002/ardp.19122500151

Miranda R, Nicu R, Latour I, Lupei M, Bobu E, Blanco A (2013) Efficiency of chitosans for the treatment of papermaking process water by dissolved air flotation. Chemical Engineering Journal 231:304-313. https://doi.org/10.1016/j.cej.2013.07.033

Mishra S, Kundu K (2019) Synthesis, characterization and applications of polyacrylamide grafted fenugreek gum (FG-g-PAM) as flocculant: microwave vs thermal synthesis approach. International Journal of Biological Macromolecules 141:792-808. https://doi.org/10.1016/j. ijbiomac.2019.09.033 
Morantes D, Munoz E, Kam D, Shoseyov O (2019) Highly charged cellulose nanocrystals applied as a water treatment flocculant. Nanomaterials 9(2):272

Mowla D, Tran HN, Allen DG (2013) A review of the properties of biosludge and its relevance to enhanced dewatering processes. Biomass and Bioenergy 58:365-378. https://doi.org/10.1016/j. biombioe.2013.09.002

Muley AB, Chaudhari SA, Mulchandani KH, Singhal RS (2018) Extraction and characterization of chitosan from prawn shell waste and its conjugation with cutinase for enhanced thermo-stability. International Journal of Biological Macromolecules 111:10471058. https://doi.org/10.1016/j.ijbiomac.2018.01.115

Nasim T, Pal A, Bandyopadhyay A (2018) Flocculation of aqueous kaolin suspension using a biodegradable flocculant system of poly (vinyl alcohol)-Acacia nilotica gum blends. Applied Clay Science 152:83-92. https://doi.org/10.1016/j.clay.2017.10.035

Negro C, Martín AB, Sanchez-Salvador JL, Campano C, Fuente E, Monte MC, Blanco A (2020) Nanocellulose and its potential use for sustainable industrial applications. Latin American Applied Research-An international journal 50(2):59-64

Nogueira GF, Fakhouri FM, de Oliveira RA (2018) Extraction and characterization of arrowroot (Maranta arundinaceae L.) starch and its application in edible films. Carbohydrate Polymers 186:64-72. https://doi.org/10.1016/j.carbpol.2018.01.024

Parviainen H, Hiltunen M, Maunu SL (2014) Preparation and flocculation behavior of cellulose-g-PMOTAC copolymer. Journal of Applied Polymer Science 131(13). https://doi.org/10.1002/app. 40448

Peng H, Zhong S, Xiang J, Lin Q, Yao C, Dong J, Yin G, Yao K, Zeng S, Zhong J (2017) Characterization and secondary sludge dewatering performance of a novel combined aluminum-ferrous-starch flocculant (CAFS). Chemical Engineering Science 173:335-345. https:// doi.org/10.1016/j.ces.2017.08.005

Prabhu M, Chemodanov A, Gottlieb R, Kazir M, Nahor O, Gozin M, Israel A, Livney YD, Golberg A (2019) Starch from the sea: the green macroalga Ulva ohnoi as a potential source for sustainable starch production in the marine biorefinery. Algal Research 37: 215-227. https://doi.org/10.1016/j.algal.2018.11.007

Rajala K, Grönfors O, Hesampour M, Mikola A (2020) Removal of microplastics from secondary wastewater treatment plant effluent by coagulation/flocculation with iron, aluminum and polyaminebased chemicals. Water Research 183:116045. https://doi.org/10. 1016/j.watres.2020.116045

Ramirez L, Gentile SR, Zimmermann S, Stoll S (2016) Comparative study of the effect of aluminum chloride, sodium alginate and chitosan on the coagulation of polystyrene micro-plastic particles. Journal of Colloid Science and Biotechnology 5(2):190-198

Rashid T, Gnanasundaram N, Appusamy A, Kait CF, Thanabalan M (2018) Enhanced lignin extraction from different species of oil palm biomass: Kinetics and optimization of extraction conditions. Industrial Crops and Products 116:122-136. https://doi.org/10. 1016/j.indcrop.2018.02.056

Reddy KO, Maheswari CU, Dhlamini MS, Mothudi BM, Kommula VP, Zhang J, Zhang J, Rajulu AV (2018) Extraction and characterization of cellulose single fibers from native african napier grass. Carbohydrate Polymers 188:85-91. https://doi.org/10.1016/j. carbpol.2018.01.110

Ren W-J, Zhang A-Q, Qin S-Y, Li Z-K (2016) Synthesis and evaluation of a novel cationic konjac glucomannan-based flocculant. Carbohydrate Polymers 144:238-244. https://doi.org/10.1016/j. carbpol.2016.02.061

Ren K, Du H, Yang Z, Tian Z, Zhang X, Yang W, Chen J (2017) Separation and sequential recovery of tetracycline and $\mathrm{Cu}$ (II) from water using reusable thermoresponsive chitosan-based flocculant. ACS Applied Materials \& Interfaces 9(11):10266-10275
Renault F, Sancey B, Badot P, Crini G (2009a) Chitosan for coagulation/ flocculation processes - an eco-friendly approach. European Polymer Journal 45(5):1337-1348

Renault F, Sancey B, Badot PM, Crini G (2009b) Chitosan for coagulation/flocculation processes - an eco-friendly approach. European Polymer Journal 45(5):1337-1348. https://doi.org/10. 1016/j.eurpolymj.2008.12.027

Roy D, Semsarilar M, Guthrie JT, Perrier S (2009) Cellulose modification by polymer grafting: a review. Chemical Society Reviews 38(7): 2046-2064

Runkana V, Somasundaran P, Kapur PC (2006) A population balance model for flocculation of colloidal suspensions by polymer bridging. Chemical Engineering Science 61(1):182-191. https://doi.org/10. 1016/j.ces.2005.01.046

Saifuddin N, Nian C, Zhan L, Ning K (2011) Chitosan-silver nanoparticles composite as point-of-use drinking water filtration system for household to remove pesticides in water. Asian Journal of Biochemistry 6(2):142-159

Salehizadeh H, Yan N (2014) Recent advances in extracellular biopolymer flocculants. Biotechnology Advances 32(8):1506-1522. https:// doi.org/10.1016/j.biotechadv.2014.10.004

Salehizadeh H, Yan N, Farnood R (2018) Recent advances in polysaccharide bio-based flocculants. Biotechnology Advances 36(1):92119. https://doi.org/10.1016/j.biotechadv.2017.10.002

Sánchez-Martín J, Beltrán-Heredia J, Solera-Hernández C (2010) Surface water and wastewater treatment using a new tannin-based coagulant. Pilot plant trials. Journal of Environmental Management 91(10): 2051-2058. https://doi.org/10.1016/j.jenvman.2010.05.013

Sanchez-Salvador JL, Balea A, Monte MC, Negro C, Blanco A (2021) Chitosan grafted/cross-linked with biodegradable polymers: a review. International Journal of Biological Macromolecules 178: 325-343. https://doi.org/10.1016/j.ijbiomac.2021.02.200

Sandberg KD, Ishii S, LaPara TM (2018) A microfluidic quantitative polymerase chain reaction method for the simultaneous analysis of dozens of antibiotic resistance and heavy metal resistance genes. Environmental Science \& Technology Letters 5(1):20-25. https:// doi.org/10.1021/acs.estlett.7b00552

Schwarzenbach RP, Escher BI, Fenner K, Hofstetter TB, Johnson CA, Von Gunten U, Wehrli B (2006) The challenge of micropollutants in aquatic systems. Science 313(5790):1072-1077

Sebastian J, Rouissi T, Brar SK, Hegde K, Verma M (2019) Microwaveassisted extraction of chitosan from Rhizopus oryzae NRRL 1526 biomass. Carbohydrate Polymers 219:431-440. https://doi.org/10. 1016/j.carbpol.2019.05.047

Sharma BR, Dhuldhoya NC, Merchant UC (2006) Flocculants-an ecofriendly approach. Journal of Polymers and The Environment 14(2):195-202

Shi C, Sun W, Sun Y, Chen L, Xu Y, Tang M (2019) Synthesis, characterization, and sludge dewaterability evaluation of the chitosanbased flocculant CCPAD. Polymers 11(1):95

Song JH, Murphy RJ, Narayan R, Davies GBH (2009) Biodegradable and compos`alternatives to conventional plastics. Philosophical Transactions of the Royal Society B: Biological Sciences 364(1526):2127-2139. https://doi.org/10.1098/rstb.2008.0289

Soon CY, Tee YB, Tan CH, Rosnita AT, Khalina A (2018) Extraction and physicochemical characterization of chitin and chitosan from Zophobas morio larvae in varying sodium hydroxide concentration. International Journal of Biological Macromolecules 108:135-142. https://doi.org/10.1016/j.ijbiomac.2017.11.138

Sun Y, Zhu C, Sun W, Xu Y, Xiao X, Zheng H, Wu H, Liu C (2017) Plasma-initiated polymerization of chitosan-based CS-g-P(AMDMDAAC) flocculant for the enhanced flocculation of low-algalturbidity water. Carbohydrate Polymers 164:222-232. https://doi. org/10.1016/j.carbpol.2017.02.010

Sun Y, Chen A, Pan S-Y, Sun W, Zhu C, Shah KJ, Zheng H (2019a) Novel chitosan-based flocculants for chromium and nickle removal 
in wastewater via integrated chelation and flocculation. Journal of Environmental Management 248:109241. https://doi.org/10.1016/j. jenvman.2019.07.012

Sun Y, Shah KJ, Sun W, Zheng H (2019b) Performance evaluation of chitosan-based flocculants with good $\mathrm{pH}$ resistance and high heavy metals removal capacity. Separation and Purification Technology 215:208-216. https://doi.org/10.1016/j.seppur.2019.01.017

Sun Y, Sun W, Shah KJ, Chiang P-C, Zheng H (2019c) Characterization and flocculation evaluation of a novel carboxylated chitosan modified flocculant by UV initiated polymerization. Carbohydrate Polymers 208:213-220. https://doi.org/10.1016/j.carbpol.2018.12. 064

Sun Y, Zhou S, Pan S-Y, Zhu S, Yu Y, Zheng H (2020a) Performance evaluation and optimization of flocculation process for removing heavy metal. Chemical Engineering Journal 385:123911. https:// doi.org/10.1016/j.cej.2019.123911

Sun Y, Zhou S, Sun W, Zhu S, Zheng H (2020b) Flocculation activity and evaluation of chitosan-based flocculant CMCTS-g-P(AM-CA) for heavy metal removal. Separation and Purification Technology 241:116737. https://doi.org/10.1016/j.seppur.2020.116737

Suopajärvi T, Liimatainen H, Hormi O, Niinimäki J (2013) Coagulationflocculation treatment of municipal wastewater based on anionized nanocelluloses. Chemical Engineering Journal 231:59-67. https:// doi.org/10.1016/j.cej.2013.07.010

Tang H, Zhang P, Kieft TL, Ryan SJ, Baker SM, Wiesmann WP, Rogelj S (2010) Antibacterial action of a novel functionalized chitosanarginine against Gram-negative bacteria. Acta Biomaterialia 6(7): 2562-2571. https://doi.org/10.1016/j.actbio.2010.01.002

Tang X, Jiang X, Zhang S, Zheng H, Tan X (2018) Recent progress on graft polymerization of natural polymer flocculants: synthesis method, mechanism and characteristic. Mini-Reviews in Organic Chemistry 15(3):227-235

Tang X, Huang T, Zhang S, Wang W, Zheng H (2020) The role of sulfonated chitosan-based flocculant in the treatment of hematite wastewater containing heavy metals. Colloids and Surfaces A: Physicochemical and Engineering Aspects 585:124070. https://doi. org/10.1016/j.colsurfa.2019.124070

Tarchoun AF, Trache D, Klapötke TM (2019) Microcrystalline cellulose from Posidonia oceanica brown algae: extraction and characterization. International Journal of Biological Macromolecules 138:837845. https://doi.org/10.1016/j.ijbiomac.2019.07.176

Taylor ML, Morris GE, Self PG, Smart RSC (2002) Kinetics of adsorption of high molecular weight anionic polyacrylamide onto kaolinite: the flocculation process. Journal of Colloid and Interface Science 250(1):28-36. https://doi.org/10.1006/jcis.2002.8341

Teodosiu C, Gilca A-F, Barjoveanu G, Fiore S (2018) Emerging pollutants removal through advanced drinking water treatment: a review on processes and environmental performances assessment. Journal of Cleaner Production 197:1210-1221. https://doi.org/10.1016/j. jclepro.2018.06.247

Tesfaye T, Johakimu JK, Chavan RB, Sithole B, Ramjugernath D (2018) Valorisation of mango seed via extraction of starch: preliminary techno-economic analysis. Clean Technologies and Environmental Policy 20(1):81-94. https://doi.org/10.1007/s10098-017-1457-3

Tolesa LD, Gupta BS, Lee M-J (2019) Chitin and chitosan production from shrimp shells using ammonium-based ionic liquids. International Journal of Biological Macromolecules 130:818-826. https://doi.org/10.1016/j.ijbiomac.2019.03.018

Varlamov VP, Mysyakina IS (2018) Chitosan in biology, microbiology, medicine, and agriculture. Microbiology 87(5):712-715. https://doi. org/10.1134/S0026261718050168

Ventura-Cruz S, Tecante A (2019) Extraction and characterization of cellulose nanofibers from Rose stems (Rosa spp.). Carbohydrate Polymers 220:53-59. https://doi.org/10.1016/j.carbpol.2019.05.053

Wang J-P, Chen Y-Z, Wang Y, Yuan S-J, Sheng G-P, Yu H-Q (2012) A novel efficient cationic flocculant prepared through grafting two monomers onto chitosan induced by Gamma radiation. RSC Advances 2(2):494-500. https://doi.org/10.1039/C1RA00473E

Wang D, Zhao T, Yan L, Mi Z, Gu Q, Zhang Y (2016a) Synthesis, characterization and evaluation of dewatering properties of chitosan-grafting DMDAAC flocculants. International Journal of Biological Macromolecules 92:761-768. https://doi.org/10.1016/j. ijbiomac.2016.07.087

Wang Y, Shi Y, Xu M, Wu L, Jia X, Wei T, Zhang S, Guo X (2016b) Smart flocculant with temperature and $\mathrm{pH}$ response derived from starch. RSC Advances 6(50):44383-44391. https://doi.org/10.1039/ C6RA04060H

Wang S, Kong F, Fatehi P, Hou Q (2018) Cationic high molecular weight lignin polymer: a flocculant for the removal of anionic azo-dyes from simulated wastewater. Molecules 23(8):2005

Wang Q, Cao Y, Zeng H, Liang Y, Ma J, Lu X (2019a) Ultrasoundenhanced zero-valent copper activation of persulfate for the degradation of bisphenol AF. Chemical Engineering Journal 378:122143. https://doi.org/10.1016/j.cej.2019.122143

Wang Z, Huang W, Yang G, Liu Y, Liu S (2019b) Preparation of cellulose-base amphoteric flocculant and its application in the treatment of wastewater. Carbohydrate Polymers 215:179-188. https:// doi.org/10.1016/j.carbpol.2019.03.097

Wei H, Gao B, Ren J, Li A, Yang H (2018a) Coagulation/flocculation in dewatering of sludge: A review. Water Research 143:608-631. https://doi.org/10.1016/j.watres.2018.07.029

Wei H, Ren J, Li A, Yang H (2018b) Sludge dewaterability of a starchbased flocculant and its combined usage with ferric chloride. Chemical Engineering Journal 349:737-747

Wu H, Liu Z, Yang H, Li A (2016) Evaluation of chain architectures and charge properties of various starch-based flocculants for flocculation of humic acid from water. Water Research 96:126-135. https://doi. org/10.1016/j.watres.2016.03.055

Wu L, Zhang X, Chen L, Zhang H, Li C, Lv Y, Xu Y, Jia X, Shi Y, Guo $\mathrm{X}$ (2018) Amphoteric starch derivatives as reusable flocculant for heavy-metal removal. RSC Advances 8(3):1274-1280. https://doi. org/10.1039/C7RA12798G

Wu P, Yi J, Feng L, Li X, Chen Y, Liu Z, Tian S, Li S, Khan S, Sun Y (2020) Microwave assisted preparation and characterization of a chitosan based flocculant for the application and evaluation of sludge flocculation and dewatering. International Journal of Biological Macromolecules 155:708-720. https://doi.org/10.1016/ j.ijbiomac.2020.04.011

Xia Z, Li J, Zhang J, Zhang X, Zheng X, Zhang J (2020) Processing and valorization of cellulose, lignin and lignocellulose using ionic liquids. Journal of Bioresources and Bioproducts 5(2):79-95. https:// doi.org/10.1016/j.jobab.2020.04.001

Xing J, Yang J-X, Li A, Ma F, Liu K-X, Wu D, Wei W (2013) Removal efficiency and mechanism of sulfamethoxazole in aqueous solution by bioflocculant MFX. Journal of Analytical Methods in Chemistry 2013:568614-568618. https://doi.org/10.1155/2013/568614

Yang Z, Shang Y, Lu Y, Chen Y, Huang X, Chen A, Jiang Y, Gu W, Qian X, Yang H, Cheng R (2011) Flocculation properties of biodegradable amphoteric chitosan-based flocculants. Chemical Engineering Journal 172(1):287-295. https://doi.org/10.1016/j.cej. 2011.05.106

Yang R, Li H, Huang M, Yang H, Li A (2016a) A review on chitosanbased flocculants and their applications in water treatment. Water Research 95:59-89

Yang Z, Ren K, Guibal E, Jia S, Shen J, Zhang X, Yang W (2016b) Removal of trace nonylphenol from water in the coexistence of suspended inorganic particles and NOMs by using a cellulosebased flocculant. Chemosphere 161:482-490. https://doi.org/10. 1016/j.chemosphere.2016.07.036

Yang K, Wang G, Chen X, Wang X, Liu F (2018) Treatment of wastewater containing $\mathrm{Cu} 2+$ using a novel macromolecular heavy metal chelating flocculant xanthated chitosan. Colloids and Surfaces A: 
Physicochemical and Engineering Aspects 558:384-391. https:// doi.org/10.1016/j.colsurfa.2018.06.082

Yates MR, Barlow CY (2013) Life cycle assessments of biodegradable, commercial biopolymers - a critical review. Resources, Conservation and Recycling 78:54-66. https://doi.org/10.1016/j. resconrec.2013.06.010

Yen H-Y, Yang M-H (2003) The effect of metal ions additives on the rheological behavior of polyacrylamide solution. Polymer Testing 22(4):389-393. https://doi.org/10.1016/S0142-9418(02)00119-8

You Y, Zhang J, Sun X (2019) Fabrication of a novel high-performance leather waste-based composite retention aid. RSC advances 9(28): 16271-16277

Zeng T, Hu X, Wu H, Yang J, Zhang H (2019) Microwave assisted synthesis and characterization of a novel bio-based flocculant from dextran and chitosan. International Journal of Biological Macromolecules 131:760-768

Zhang W, Wang H, Li L, Li D, Wang Q, Xu Q, Wang D (2019) Impact of molecular structure and charge property of chitosan based polymers on flocculation conditioning of advanced anaerobically digested sludge for dewaterability improvement. Science of The Total
Environment 670:98-109. https://doi.org/10.1016/j.scitotenv.2019. 03.156

Zhao C, Zheng H, Sun Y, Zhang S, Liang J, Liu Y, An Y (2018) Evaluation of a novel dextran-based flocculant on treatment of dye wastewater: effect of kaolin particles. Science of The Total Environment 640-641:243-254. https://doi.org/10.1016/j.scitotenv. 2018.05.286

Zheng C, Zheng H, Wang Y, Wang Y, Qu W, An Q, Liu Y (2018) Synthesis of novel modified magnetic chitosan particles and their adsorption performance toward $\mathrm{Cr}(\mathrm{VI})$. Bioresource Technology 267:1-8

Zheng C, Zheng H, Wang Y, Sun Y, An Y, Liu H, Liu S (2019) Modified magnetic chitosan microparticles as novel superior adsorbents with huge "force field" for capturing food dyes. Journal of Hazardous Materials 367:492-503. https://doi.org/10.1016/j.jhazmat.2018.12. 120

Publisher's note Springer Nature remains neutral with regard to jurisdictional claims in published maps and institutional affiliations. 